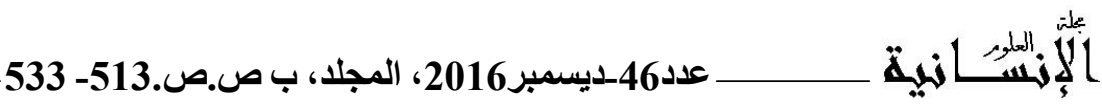

\title{
الحماية المستدامة للساحل في ظل القانون الجزائري
}

\author{
حسينة غواس \\ كلية الحقوق \\ جامعة الإخوة منتوري، قسنطينة
}

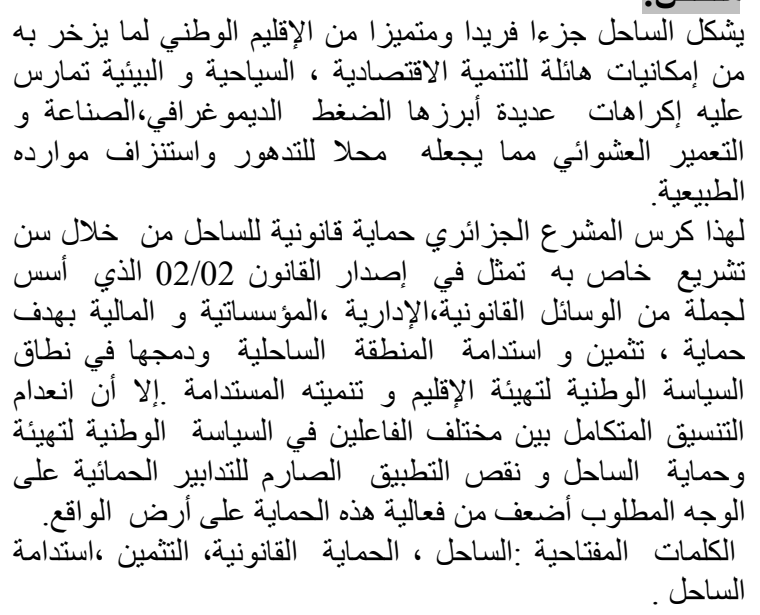

\section{مقدّمة:}

يتوافر الساحل1 الجزائري على مميزات ومقومات خاصة طبيعية ،اقتصادية، بيئية الفئية

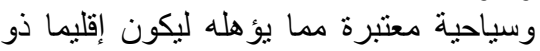

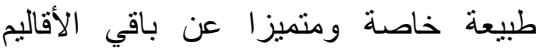

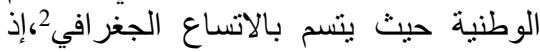

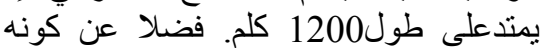

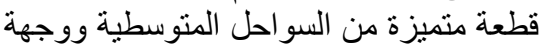

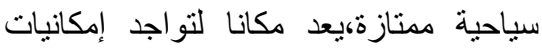

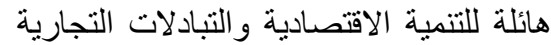

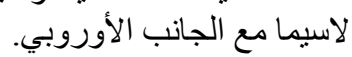

فالبنظر إلى هذه المقومات الألهائلة،جاءت فكرة

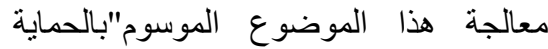

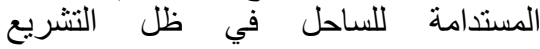
الجزائري"،بالبحث عن الحماية التي يوفرها

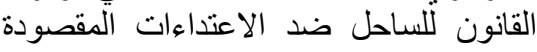

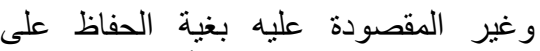
سلامة مقوماته البيئة لفائدة الأجيال القادمة.

\section{Abstract:}

The littoral constitutes an unequalled and distinguished part of the national territory because it is bubbled over with the tremendous potentialities of the economic touristic and environmental development, it endures a various constraints especially the demographic compression industry and the hazardous peopling this leads to a degradation and drain of its national resources. For this reason the Algerian legislator has ratified a law protection for the littoral by the enactment of a special legislation represented by the promulgation of the law $02 / 02$ which is constituted for a group of legal administrative, institutional and financial means in order to protect, appreciate and preserve the littoral region and its integration in the national politic area to arrange the environment and to preserve its development. But the lack of a complete coordination between the various makers in the national politic for the arrangement and the protection of the littoral and the insufficient of the severe implementation of the protection measures suitably has weaken the efficacy of this protection in reality.

Key words: The littoral, the legal protection, estimation, preservation of the littoral. 


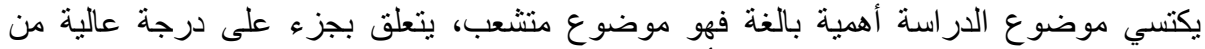

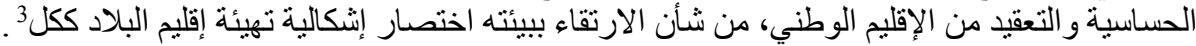

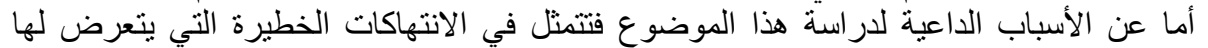

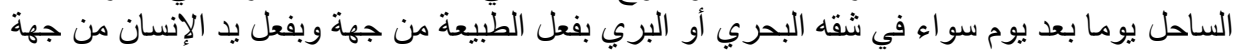

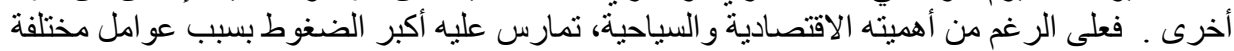

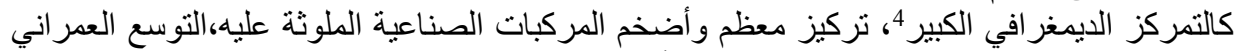

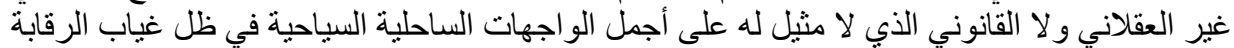

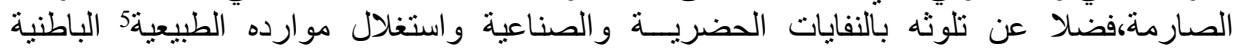

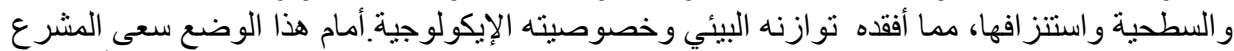

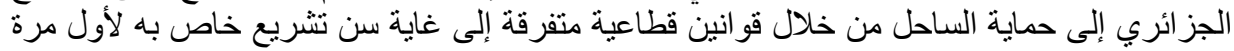

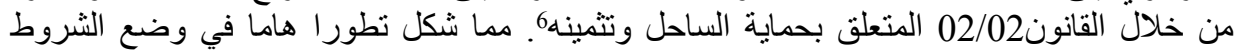

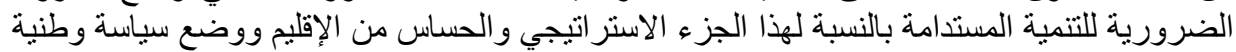

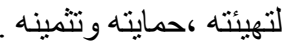

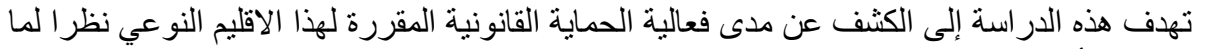

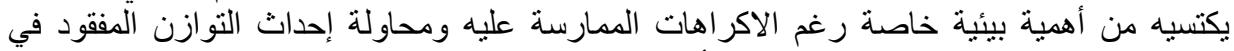

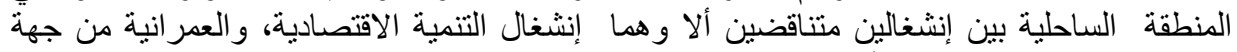

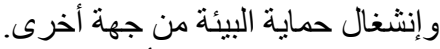

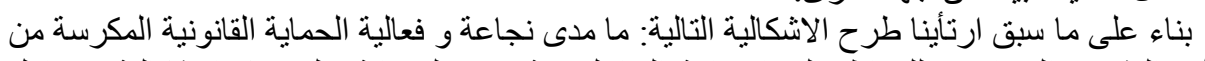

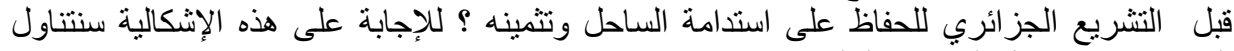
الموضوع من خلال المبحثين التاليين: ـ المبحث الأول: الأحكام العامة المتعلقة بالبيئة الساحلية. ـ ـ المبحث الثاني: الآليات القانونية لحماية البئية العائة الساحلية. المبحث الأول: الأحكام العامة المتعلقة بالبيئة الساحلية.

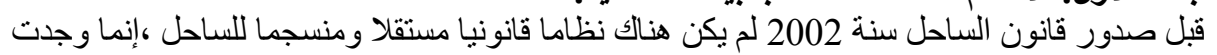

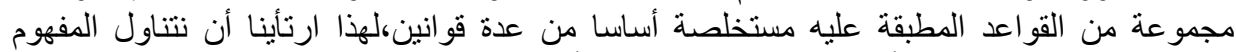

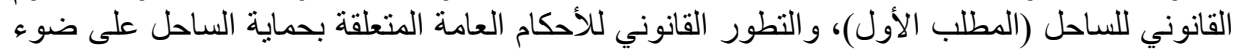

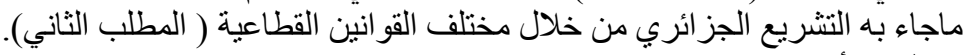
المطلب الأول: المفهوم القانوني للساحل.

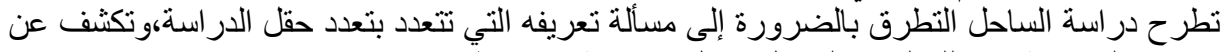

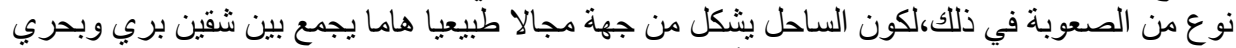

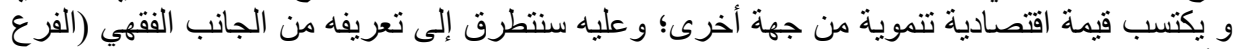

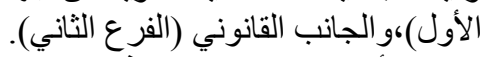

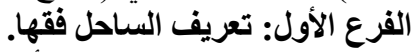

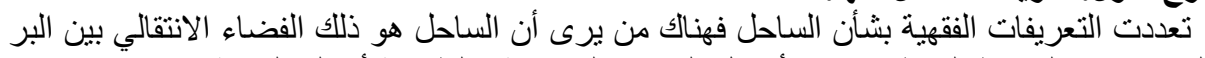

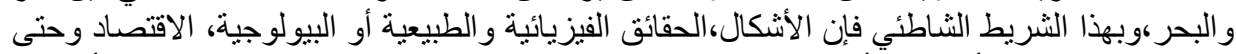

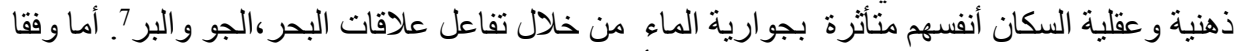

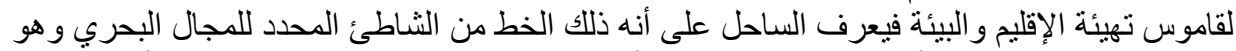

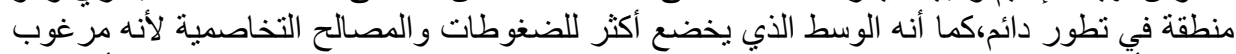

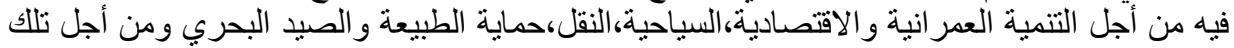

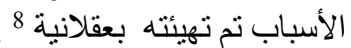
يمكن أن أقدم تعريفي الخاص للساحل على أنه منطقة إلتقاء البر بالبحر ،لهاعرض وطول محددين،تمثل 
الجزء الأكثر هشانشة من الإقليم الوطني و الأكبر عرضة لضغوط التنمية،تتميز بتنو عهاو غناها بالموارد الطبيعية وقدر اتها البيئية الهائلة. القرع الثاني: تعريف الساحل قانونانيا. من الناحية التشريعية عرف الساحل بموجب المانية المادة الأولى من القانون الفرنسي الصادر بتاريخ

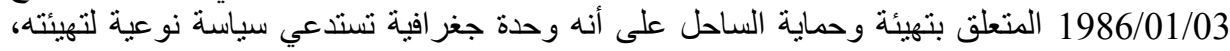
حمايته وتثمينهُ. أما المشر ع الجز ائري فلم يحدد تعريفا قانونيا دقيقا للساحل في قانون 02/02 102،بل اكتفى في ذلك بتحديد

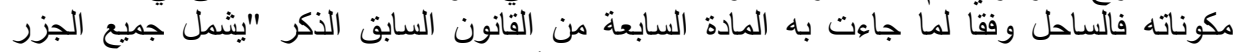

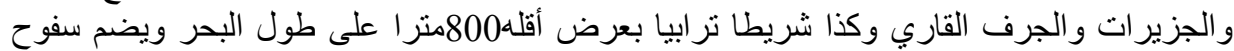

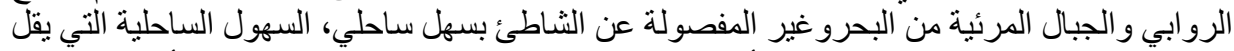

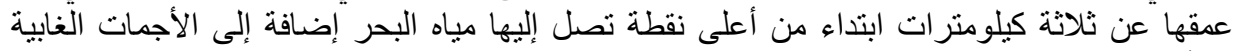

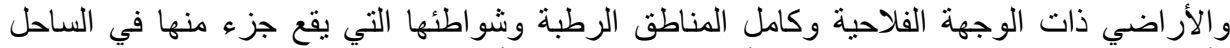

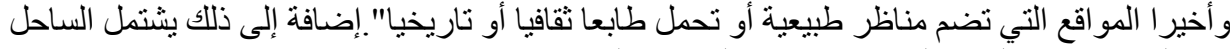

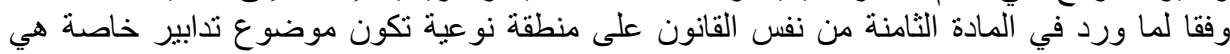

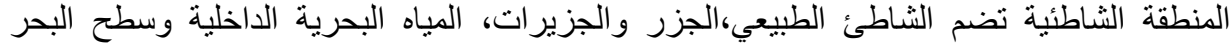

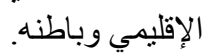

يستخلص من هذا التعريف أن الساحل الجزائري يتشكل من شق بري وآخر بحري حيث يمتد هذا

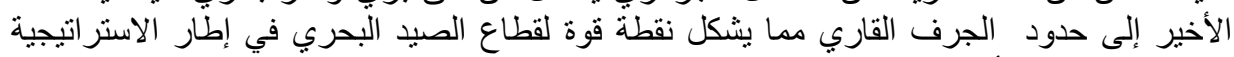

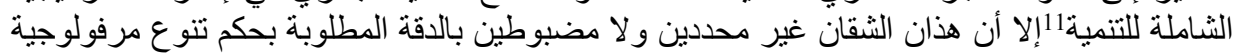

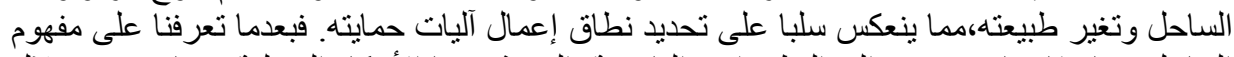

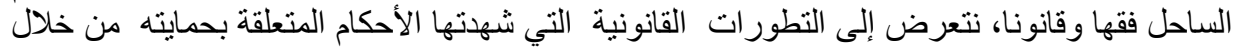

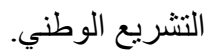
المطلب الثاني: التطور القانوني للأحكام المتعلقة بحماية الساحل.

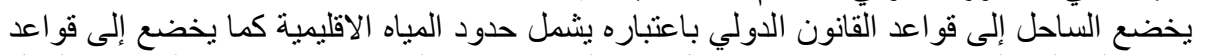

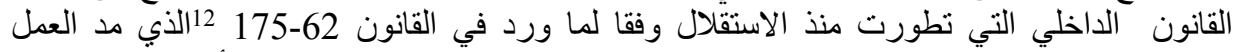

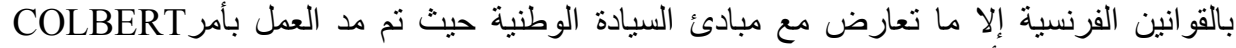

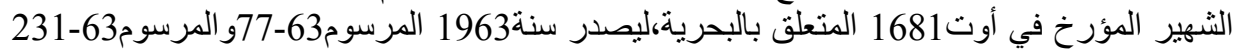

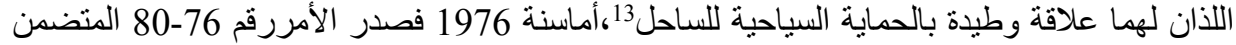

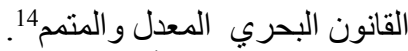

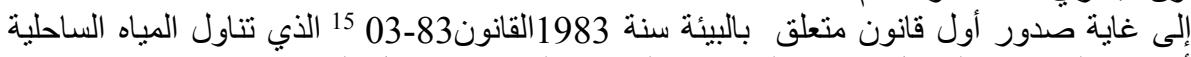

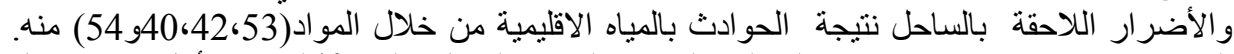

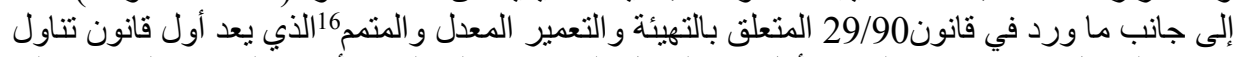

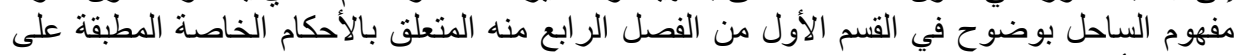

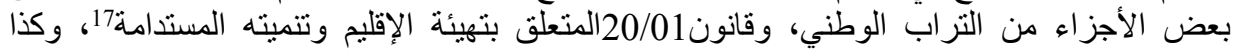

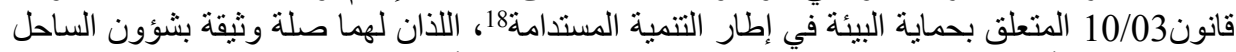

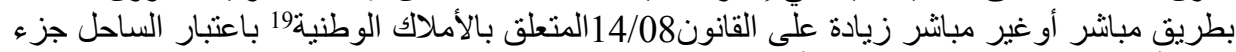

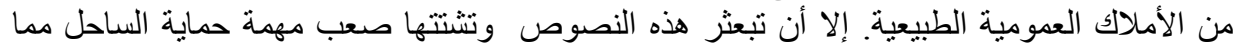

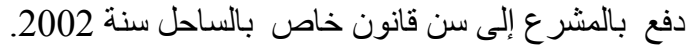

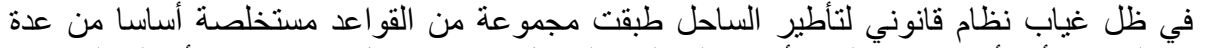

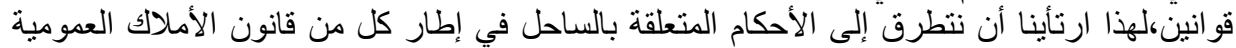
الوطنية (الفرع الأول) ،قانون التهيئة و التعمير (الفرع الثناني) وقانون تهيئة الاقليم وتتميته الإنه 


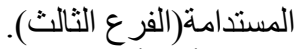

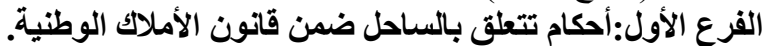

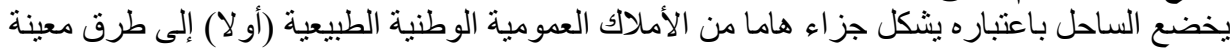
لاستعماله واستغلاله بما يتو افق مع خاصيته الايكولوجية(ثانيا).

أولا: الساحل جزء من الأملاك الوطنية العمومية.

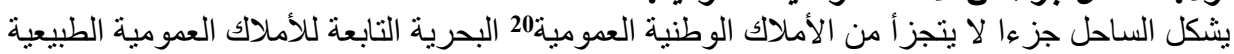

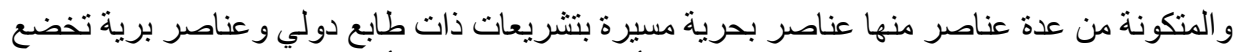

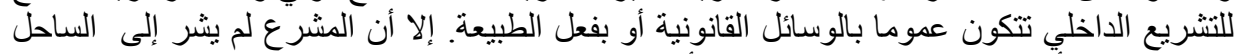

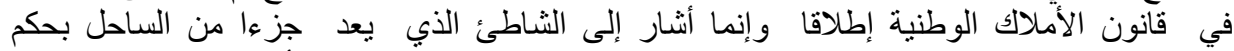

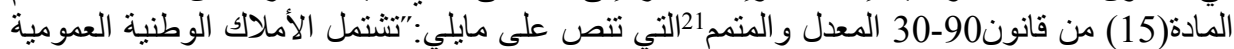

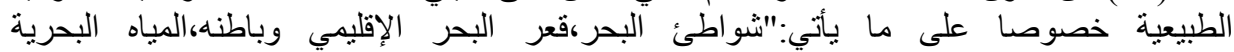

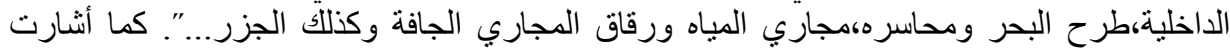

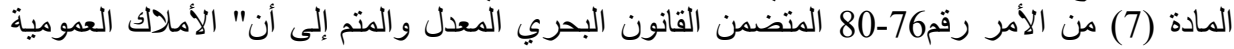

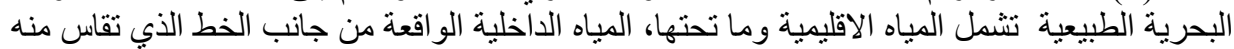

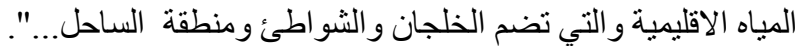

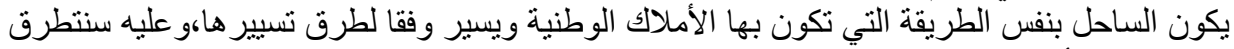

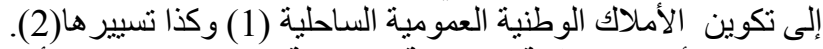

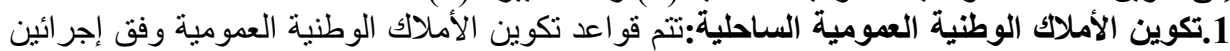

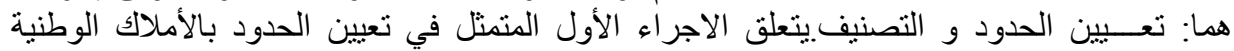

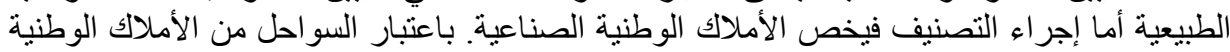

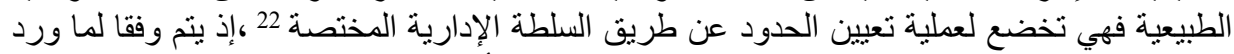

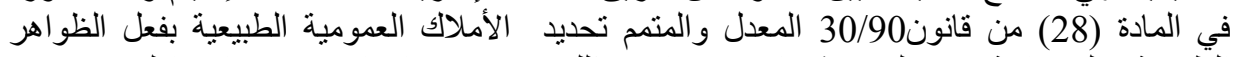

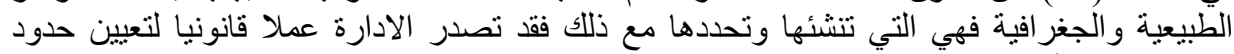

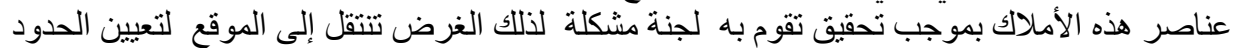

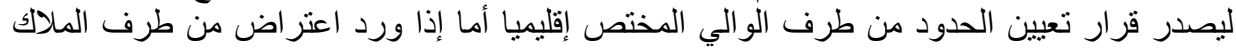

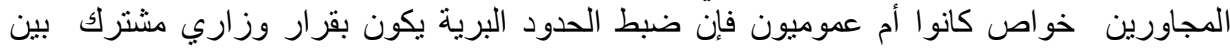

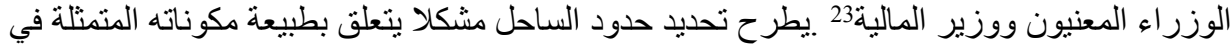

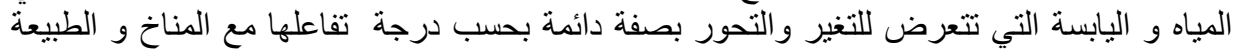

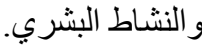

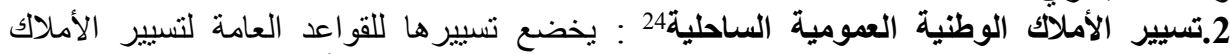

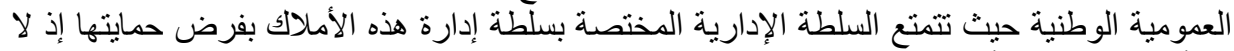

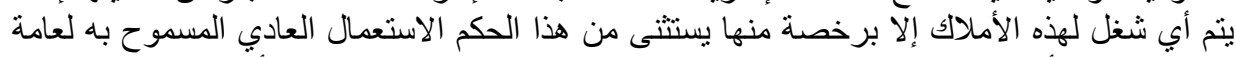

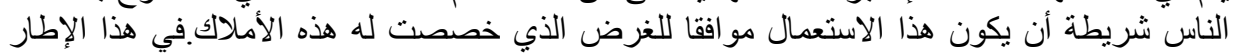

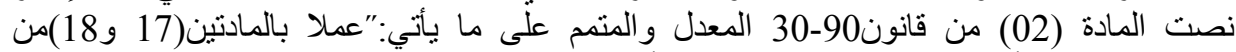

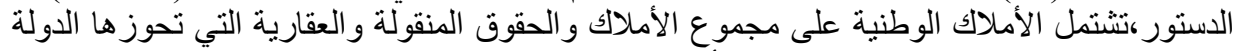

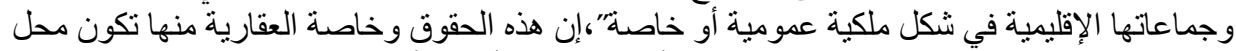

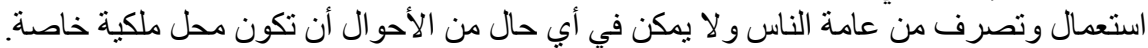

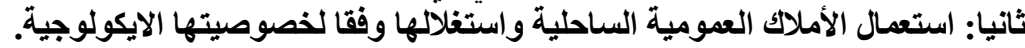

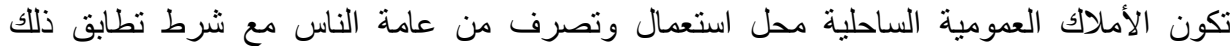
الاستعمال مع تخصيصهاو مقوماتها الايكولوجية ولندال ولعدم إحاق أي أضرار بها. 


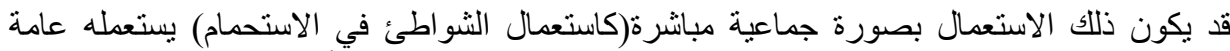

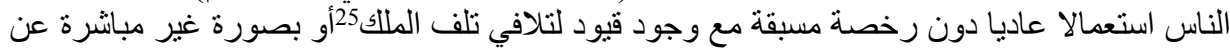

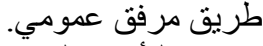

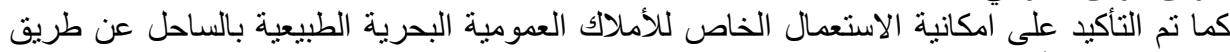

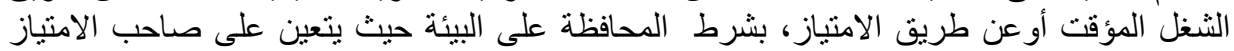

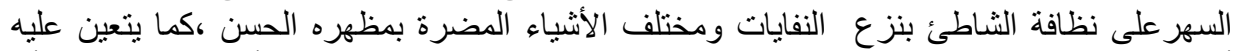

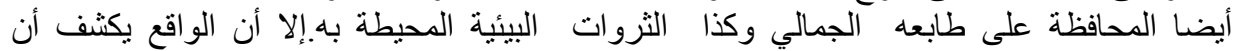

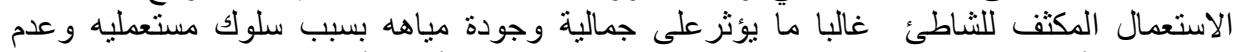

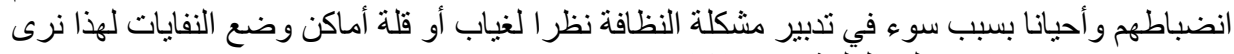

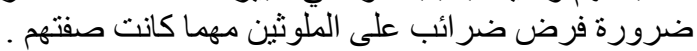

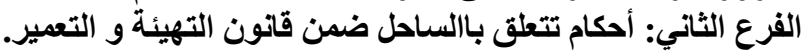

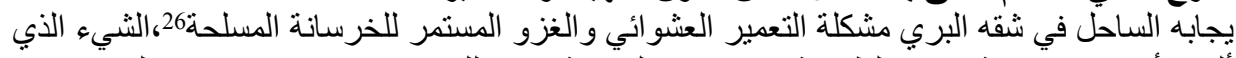

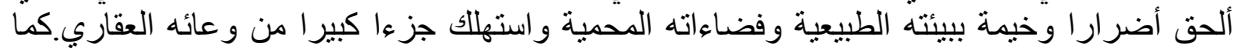

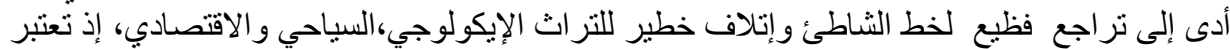

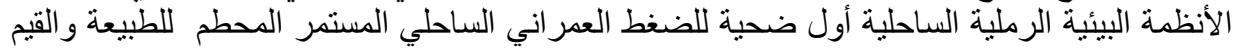

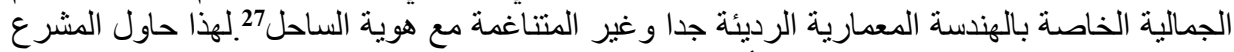

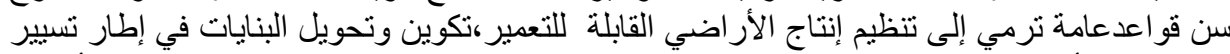

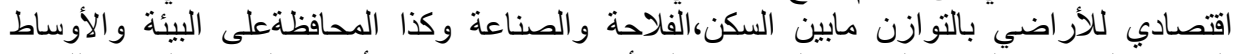

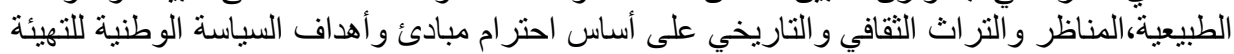

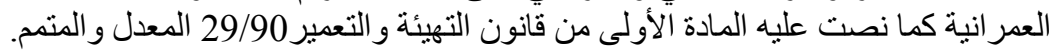

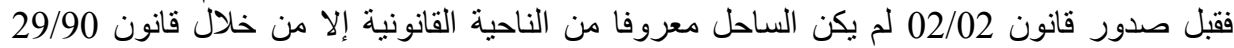

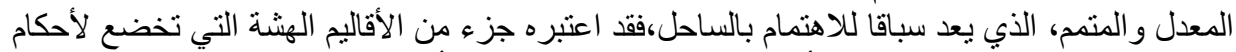

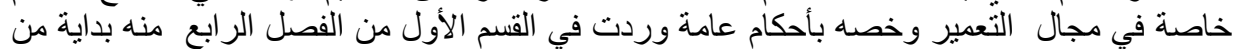

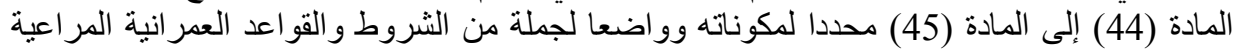

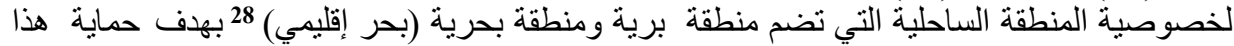

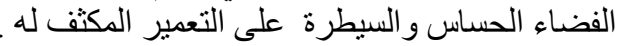

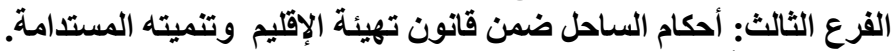

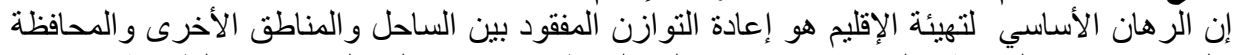

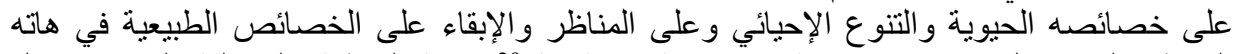

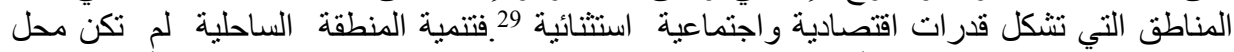

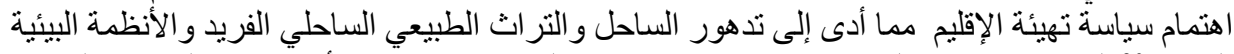

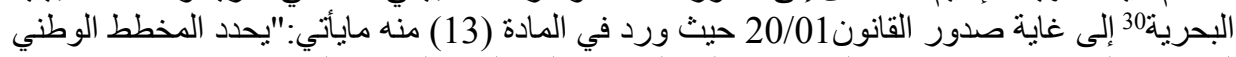

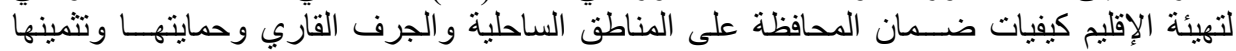

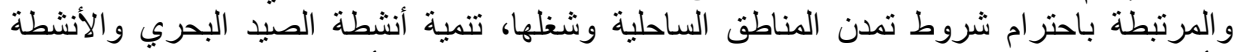

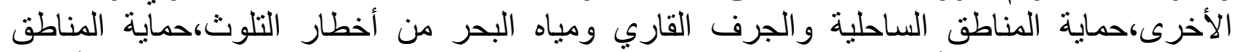

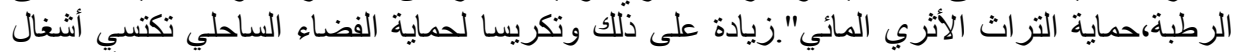

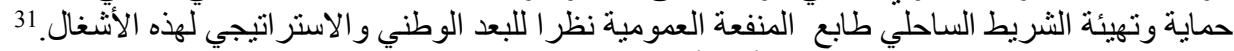

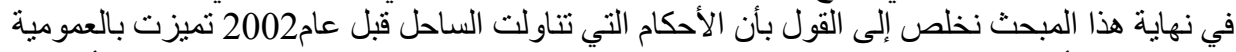

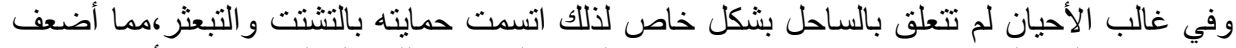

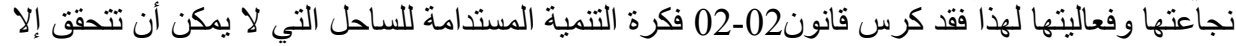

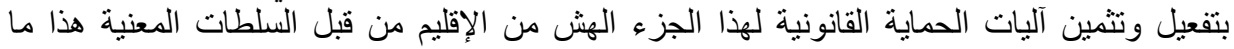




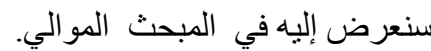

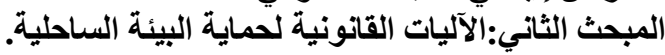

كرس المشرع آليات فانونية لحماية الساحل،تعبر عن الرقابة الرقابة القبلية و البعدية ونتمثل في آليات فانونية

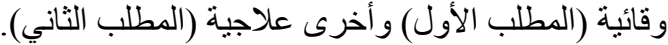
المطلب الأول:الآليات القانونية الأولية الوقائية.

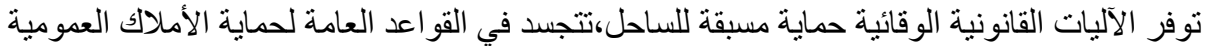

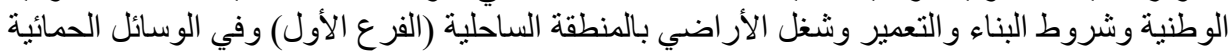

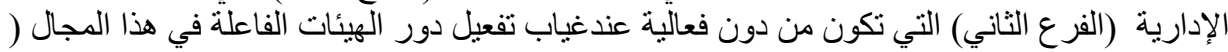

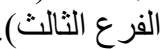
الفرع الأول: الحماية الوقائية للساحل في إطار قواعد الأملاك العمومية الوطنية وقواعد البناء و التعمير.

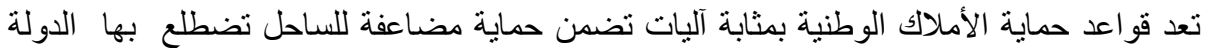

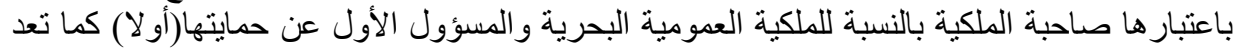
قو اعد البناء والتعمير وشروط شغل شاهي المنطقة الساحلية آليات اضافية لحمايتها أمام أخطار التوسع العمر اني(ثانيا).

أولا: حماية الساحل في إطار القواعد العائان العامة للأملاك العمومية الوطنية.

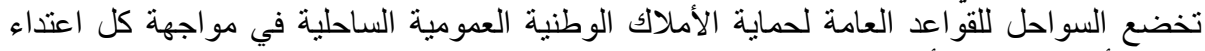

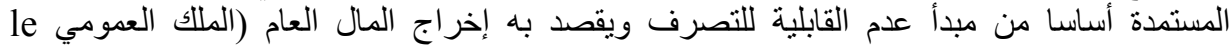
(domaine public العمومية بموجب نص المادة (04) من قانون

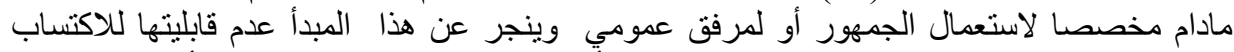
بالتقادم و عدم قابلية الحجز عليها،ينتج عن هذا المبدأ متابعة الإدارة لكل من يشغل هذب الأملاك العدومية

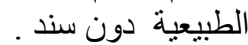

حماية للملك العمومي الساحلي تبادر الإدارة بإجر اءات جرد هذه الممتلكات لكي تتمكن من حمايتها

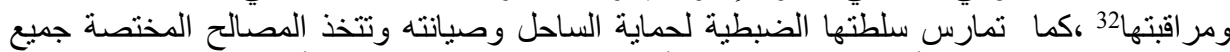

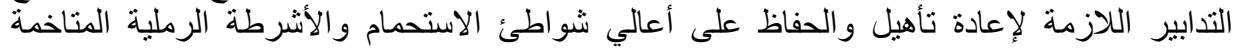

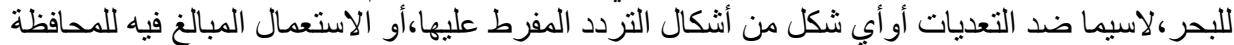

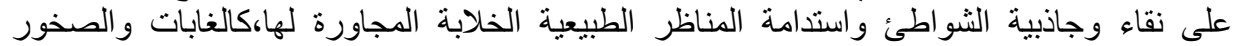

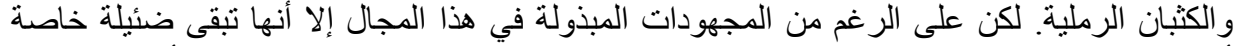

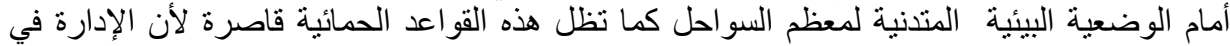

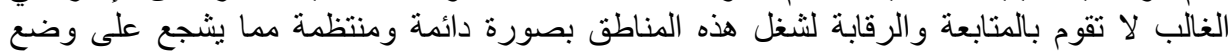

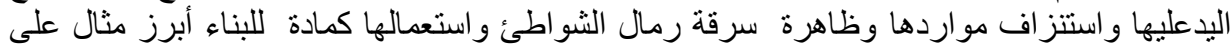

ثاتيا:حماية الساحل في إطار قواعد البناء والتعمير.

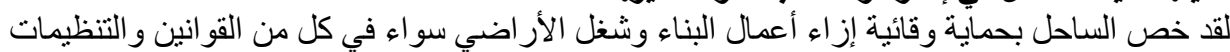

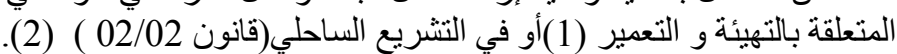

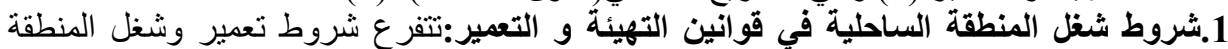

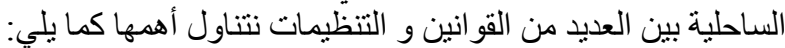

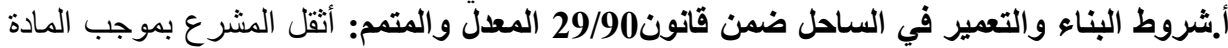

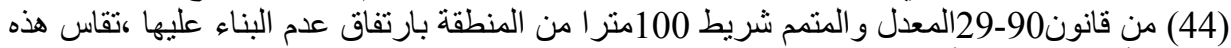
المسافة أفقيا من نقطة أعلى المياه ،لكن هذا لا يعني تحريم البناء في المنطقة بصورة نهائية بل يمكن النياء 


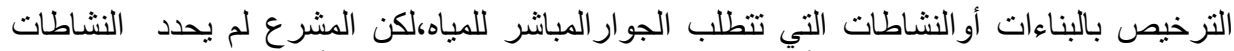

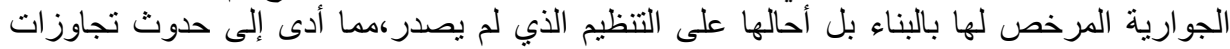

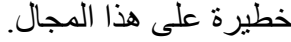

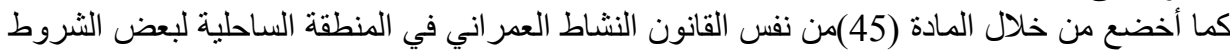

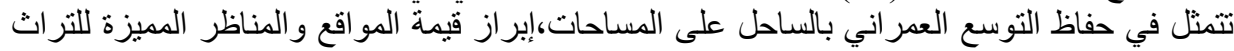

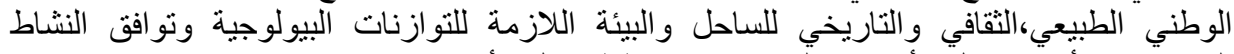

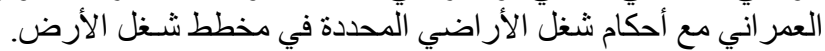

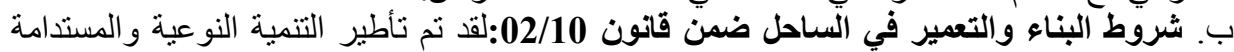

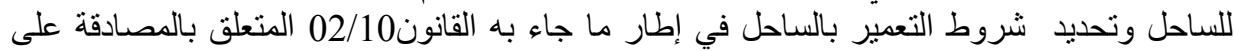

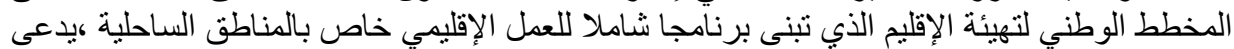

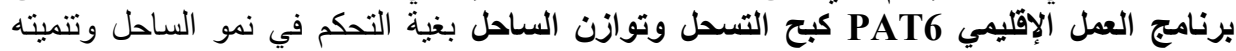

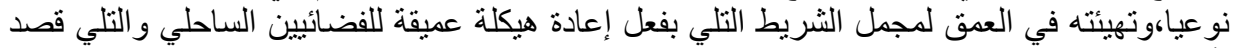

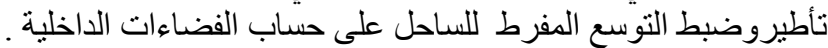
يهذف هذا البرنامج إلى تحقيق الأهداف التالية:

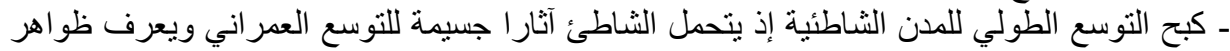

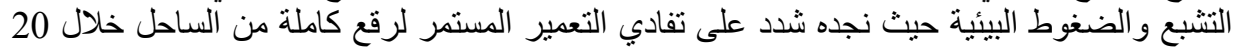

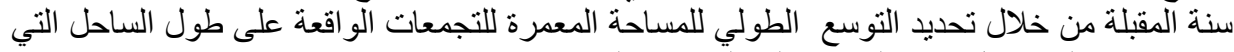

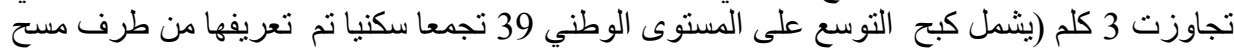
الساحل من بين 92 بلدية شاطئية).

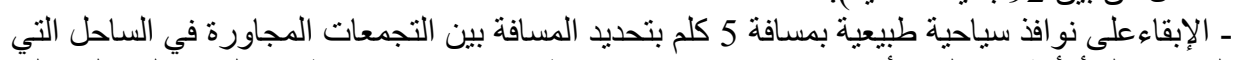

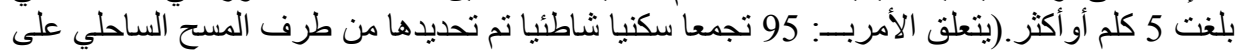

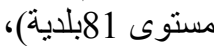

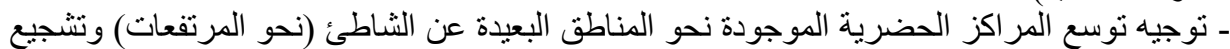

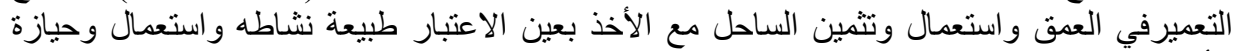

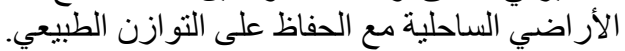

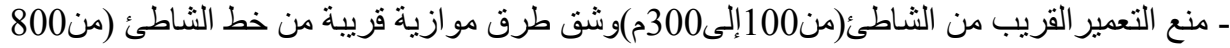

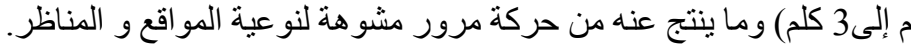

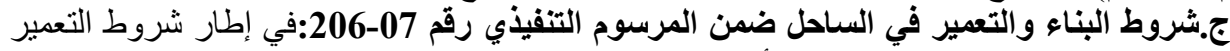

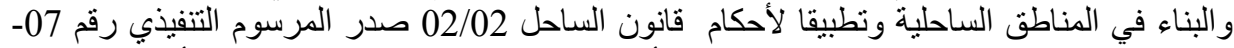

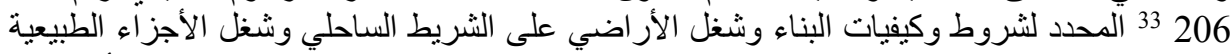

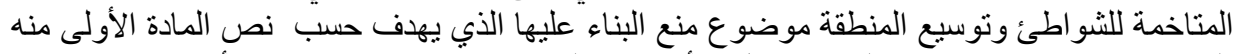

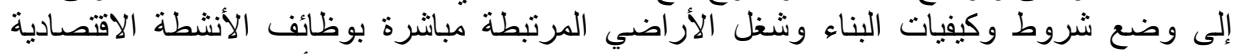

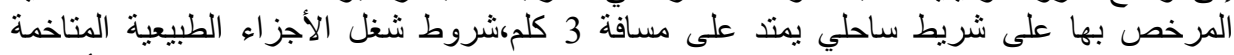

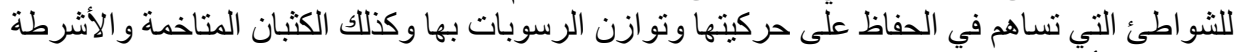

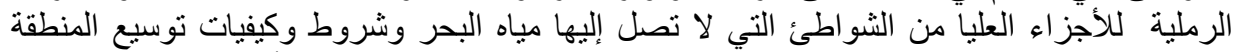

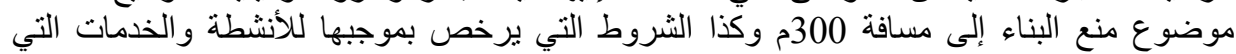
تقتضي مجاورة البحر.

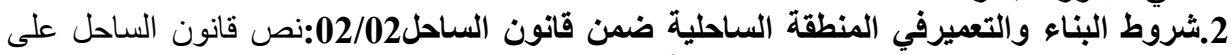

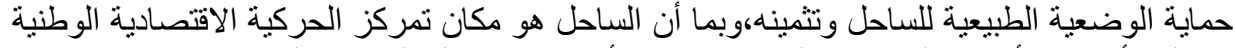

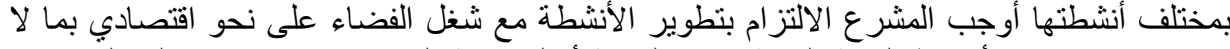

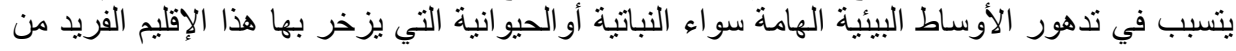




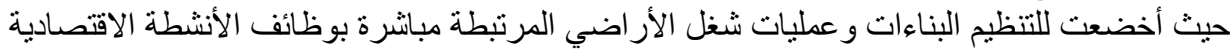

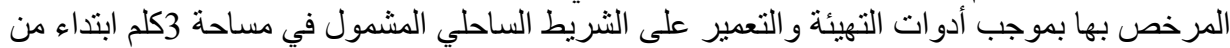

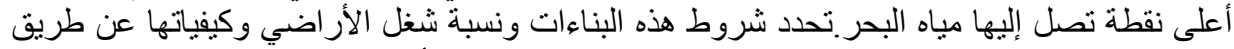

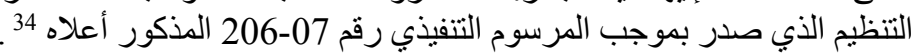

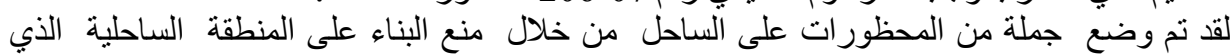

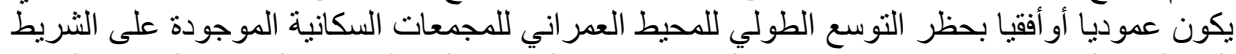

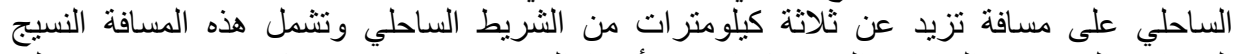

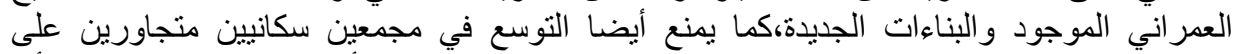

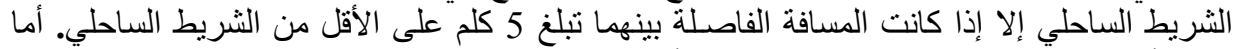

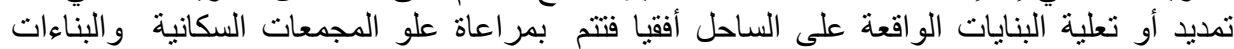

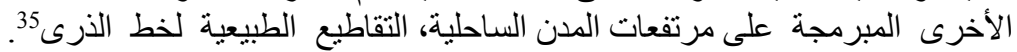

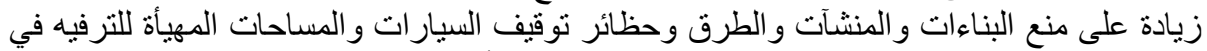

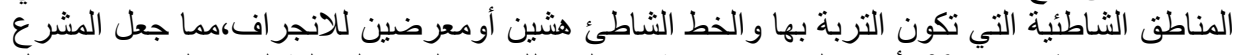

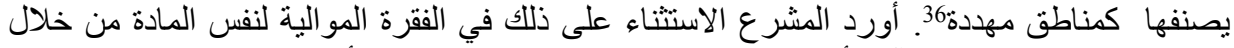

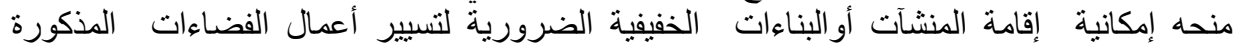

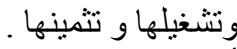

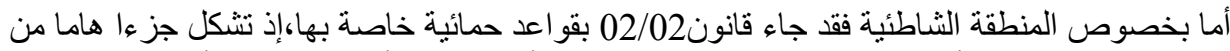

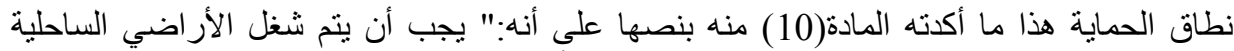

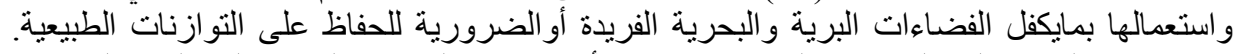

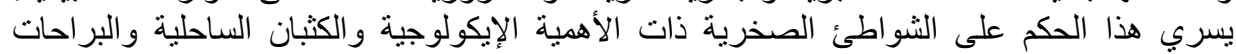

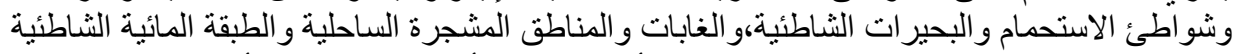

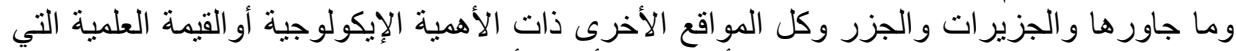

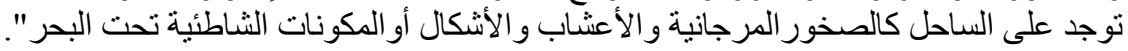

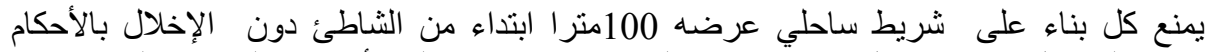

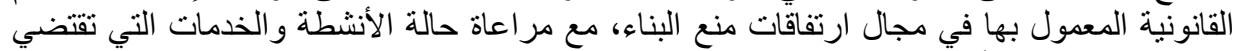

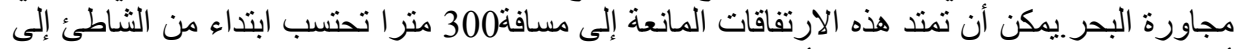

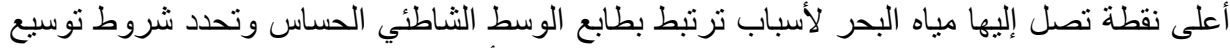

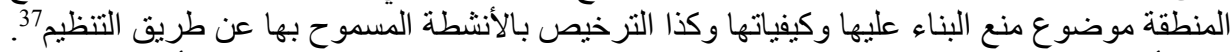

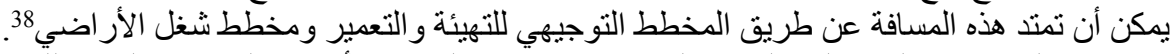

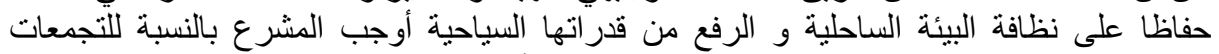

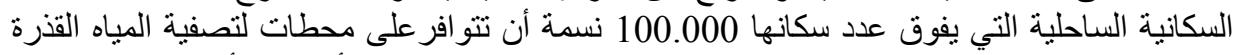

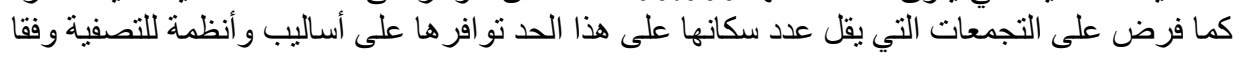
لمانصت عليه المادة(22) من قانون التون الساحل.

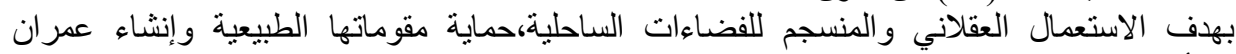

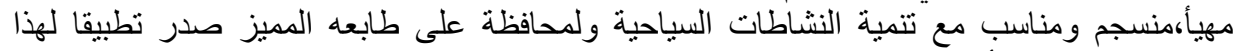

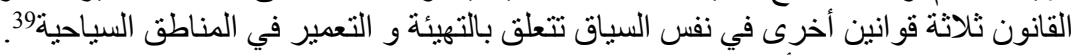

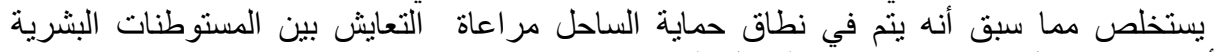

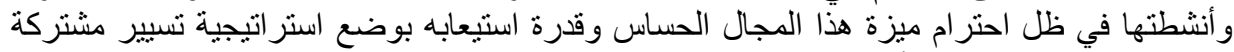

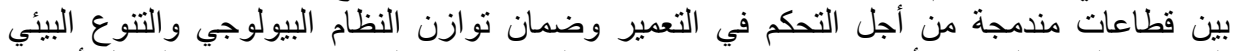

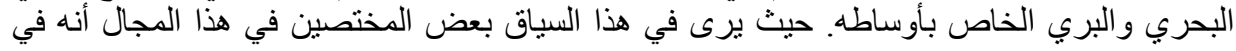


الو اقع عندما بطبق كل من قانون العمران وقانون البيئة على الساحل تظهر علاقة القوى مابين غايتين

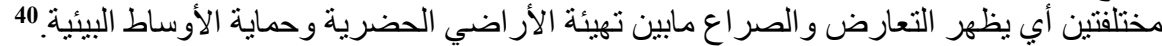

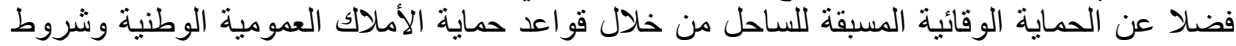

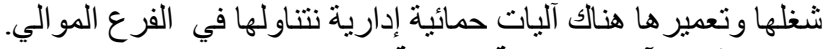
الفرع الثاني: آليات الحماية الإدارية. تتجسد الحماية الإدارية للساحل من خلإلال الإية الاعتماد على نظام التخطيط (أولا) و على الدراسات البيئة

المتعلقة بالمنطقة الساحلية (ثانيا).

أولا:التخطيط آلية استراتيجية لتهيئة المنطقة الساحلية.

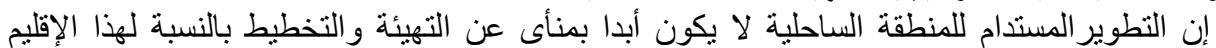

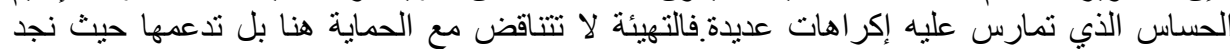

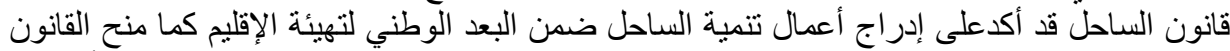

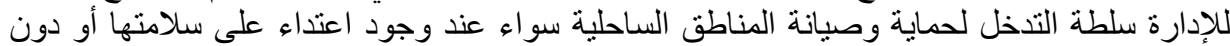

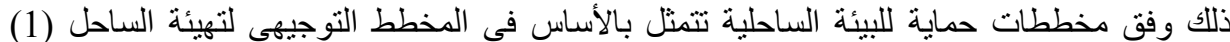
،خطط تهيئة المنطقة الثاطئية (2)و مخططات استعجالية (3). 1.المخطط التوجيهي لتهيئة الساحل(SDAL):بدأ الاهتمام الفعلي بتهيئة المنطقة الساحلية من خلال

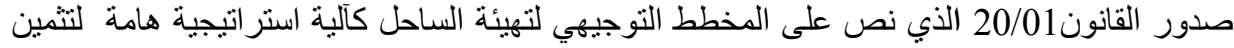

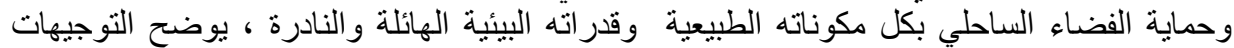

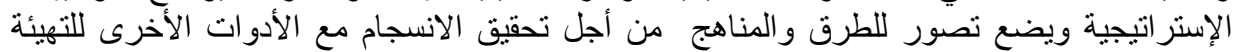

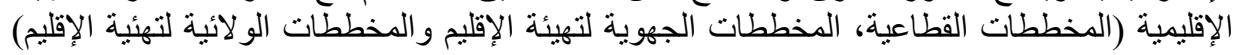

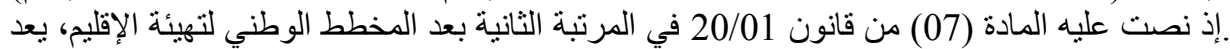

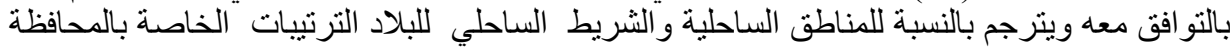

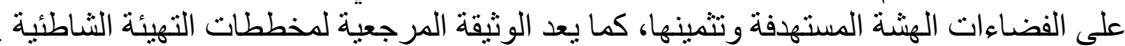

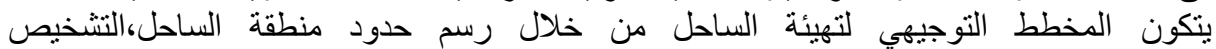

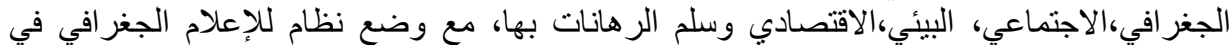

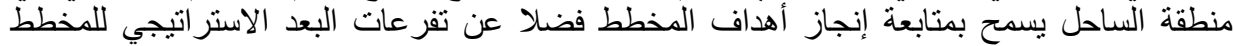

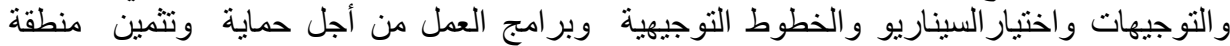
يقتر ح المخطط التو جيهي لتهيئة الساحل إجراءات ملموسة ذات أولوية مفصلة و وفقا لحالة استعجالها

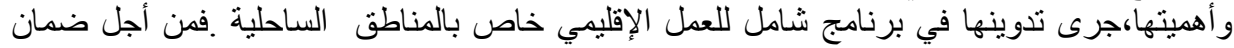

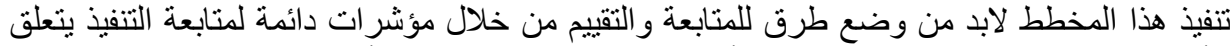

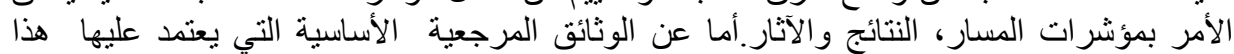

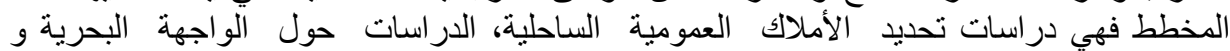
دراسات خاصة بالبلديات و الو لايات الساحلية.

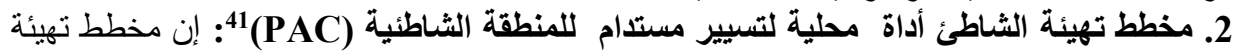

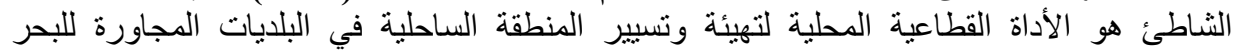

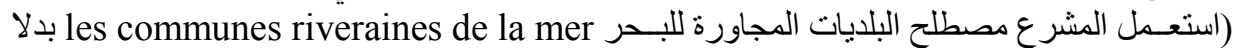

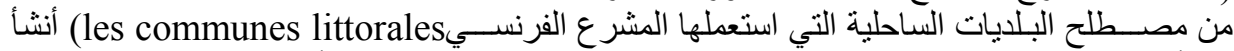

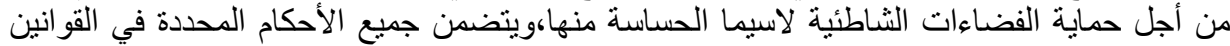

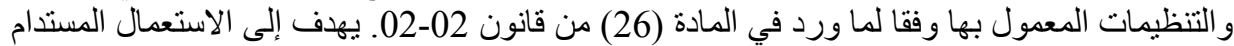

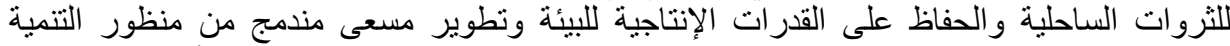
الساحلية المستدامة.تحدد شروط إعداده،محتو اه وكيفيات تتفيذه عن طريق التنظيم هذا الأخير الذي صدر 
سنة 2009 بموجب المرسوم التنفيذي رقم 09-114 42. وضع هذا المخطط لتهيئة وتسيير المنطقة الساحلية في البلديات المجاورة للبحر،من أجل حماية

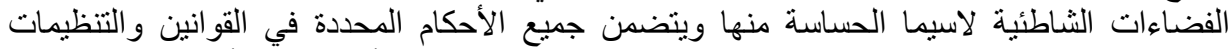

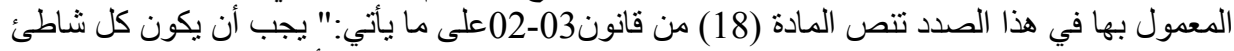

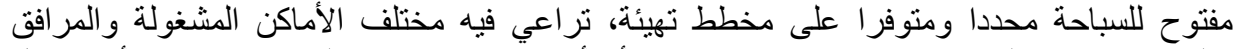

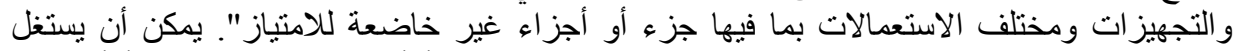

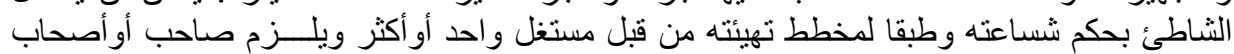

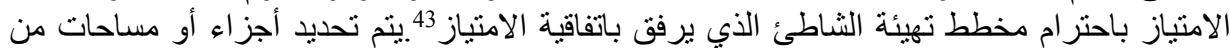

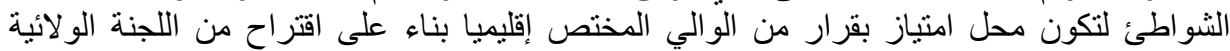

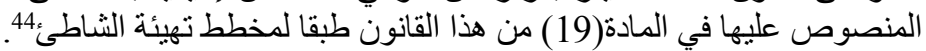

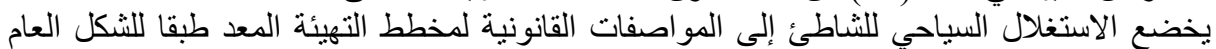

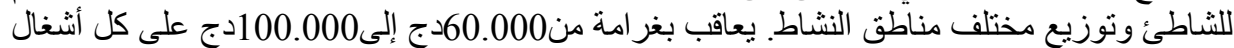
تهيئة أو تجهيز مخالفة لشروط مخطط تهيئة الثاطئ وفي حالة العود يعاقب بالحبس من 6 أشهر إلى

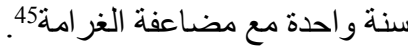
يتضمن مخطط تهيئة الثاطئ تقرير ا تقنيا و نظاما لتهيئة وتسيير الساحل.أما التقرير التقني فيبرز تحـديد

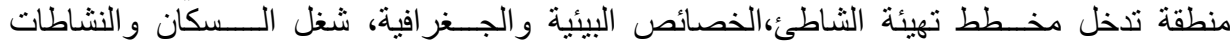

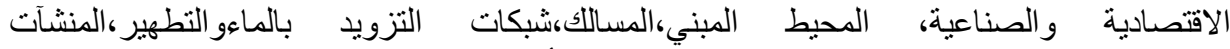

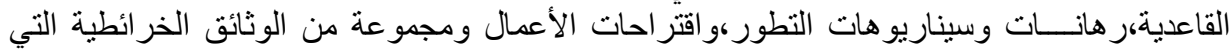

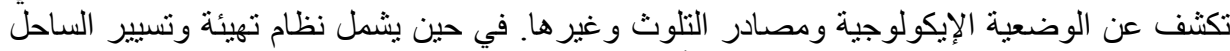

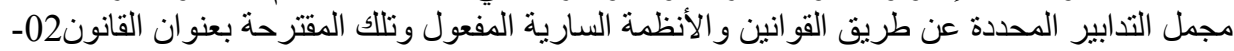

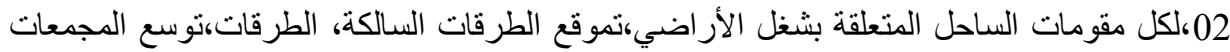

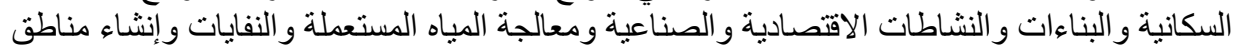

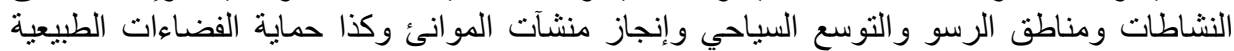

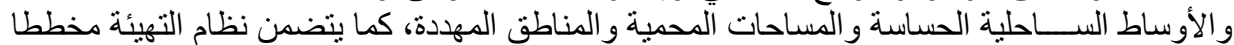
خر ائطيا أيضنا.

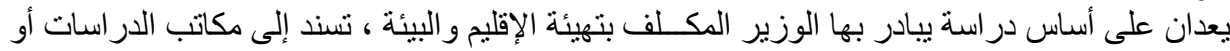

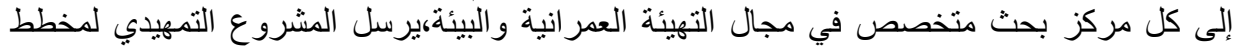

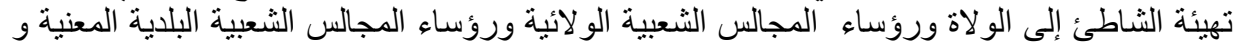

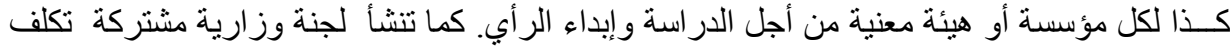

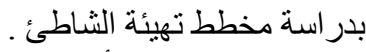

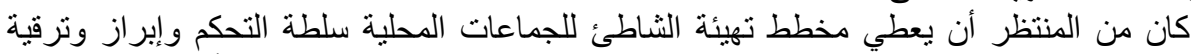

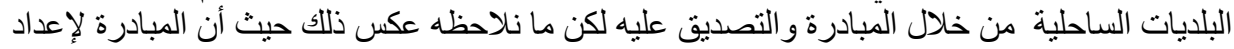

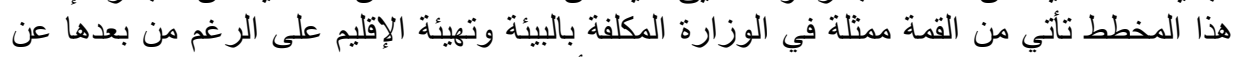

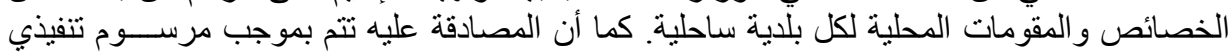

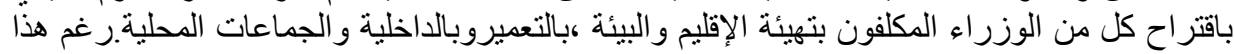

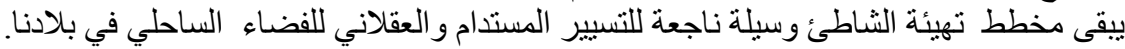

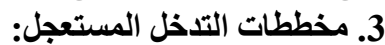
تنشأ مخططات للتنخل المستعجل فيما يخص حاتل فالات التلوث في الساحل أو في المناطق الثاطئية أو في

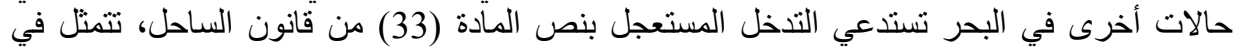

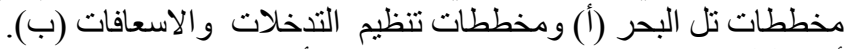
أ.مخطط تل البحر:يعد هذا المخطط الوطني أداة لمكافحة التلوث البحري الناجم عن حوادث في البرأو 


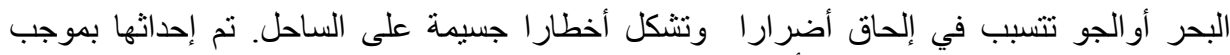

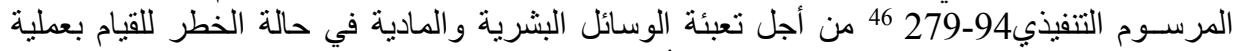

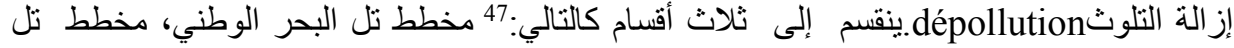
البحر الجهوي و مخطط تل البحر الو لأبئي.

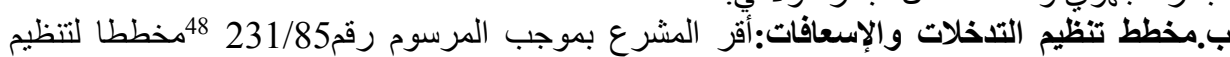

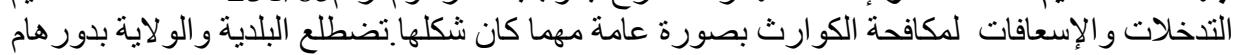

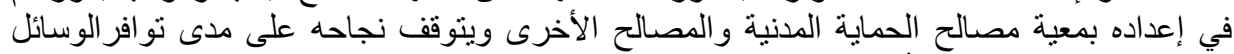

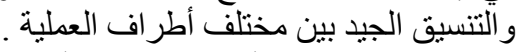

ثانيا: الاراسات البيئية كآليات قانونية مسبقة لحماية البيئة الساحلية.

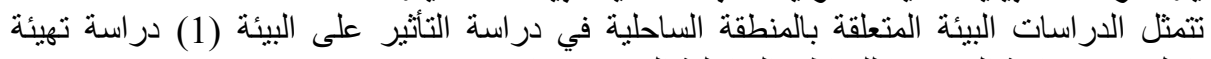

الساحل(2) ودراسة التصنيف للمناطق الساحلية المهددة بيئيا (3).

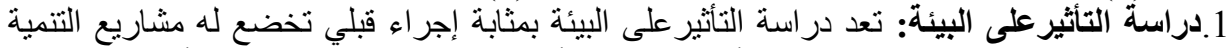

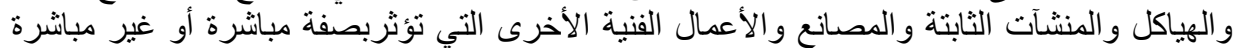

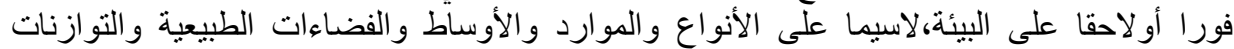

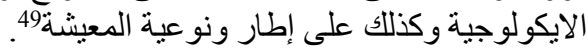

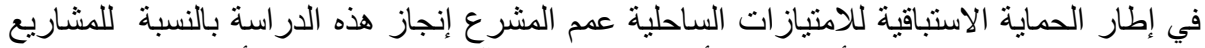

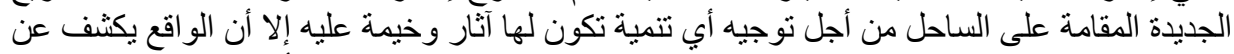

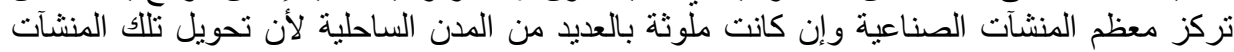

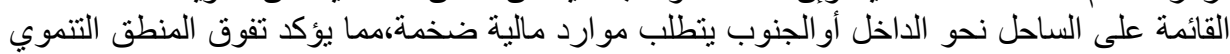
حتى و إن كان على حساب البيأنة. 2.دراسة تهيئة الساحل:نظرا لكون الساحل ينتمي إلى المناطق ذات الطابع الإيكولوجي، الطبيعي،

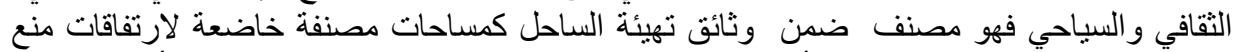

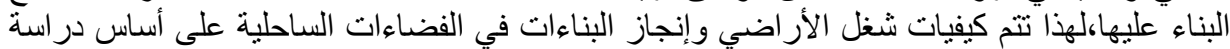
تدعى دراسة تهيئة الساحل نطاق تطبيق هذه الدراسة أو الفضاءات المشمولة بها هي الأجزاء الطبيعية المتاخمة للشواطئ و التئي

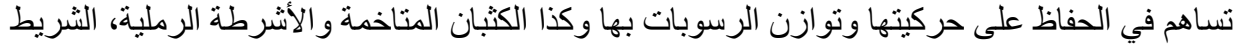

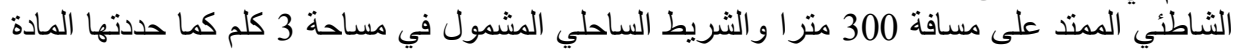

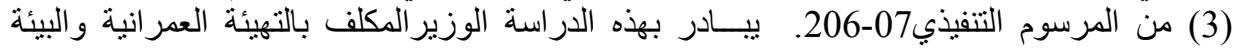

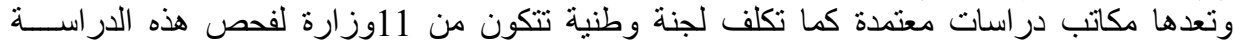

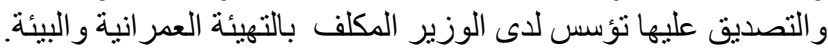

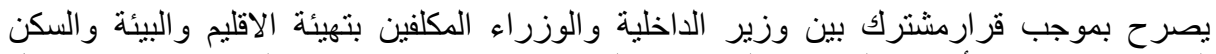

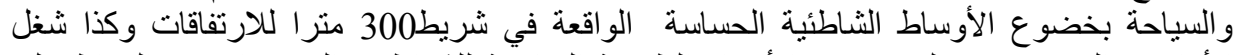

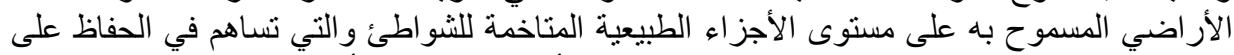

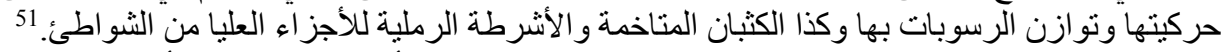

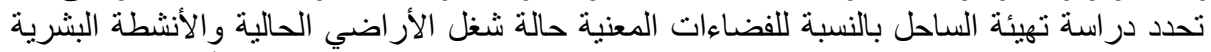

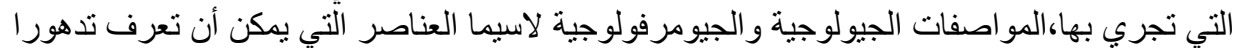

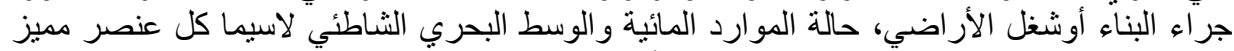

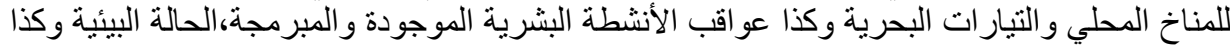

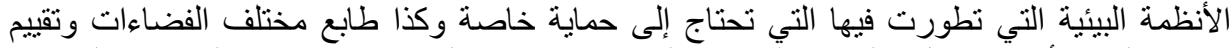

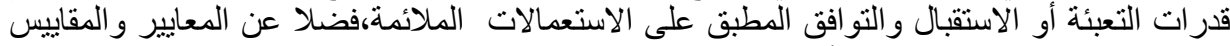
و المؤشرات ولمعطيات المهمة الأخرى المستعملة لإعداد هذه الدراسة. 52 
3. دراسة التصنيف: تدعيما لهذه الحماية يتم تصنيف بعض المناطق المهددة من الساحل وفقا لما

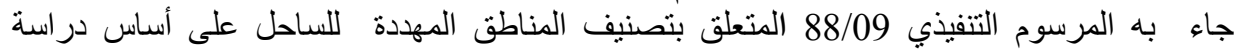

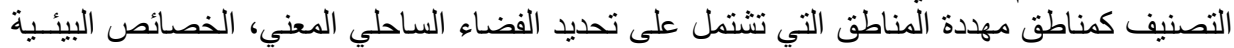

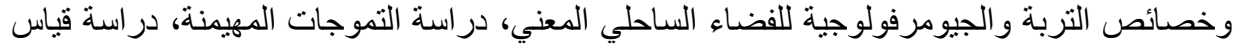

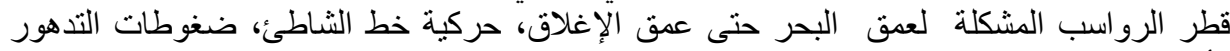

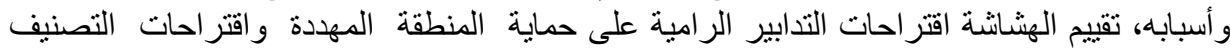
كمنطقة مهددة 53 .

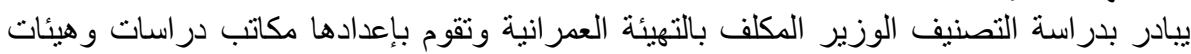

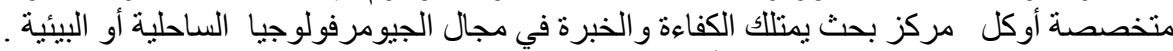
لكن لا يمكن لآليات الحماية الإدارية أن يكتب لهاء النجاح من دون وجود هيئات فعالة لتجسيدها على لئل

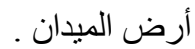

الفرع الثالث:آليات الحماية المؤسساتية.

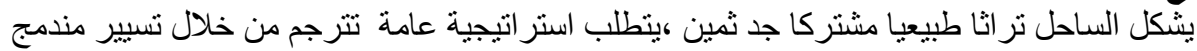

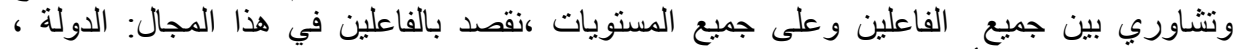

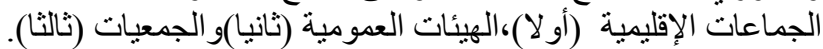
أولا :دور الدولة والجماعات الإقليمية في حماية البيئة الساحلية.

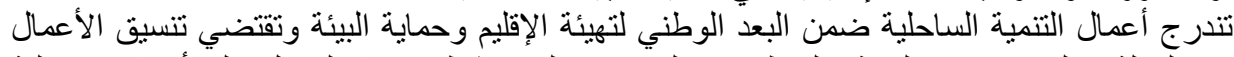

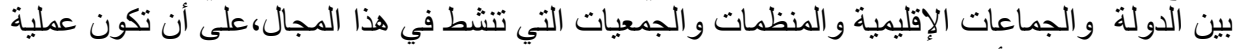

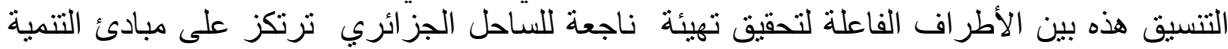
المستدامة و الوقاية والحيطة المبن. فضلا على التتسيق بين الفاعلين أقر المشرع مبدأ العمل على توجيه توسع ونمو المراكز الحضرية

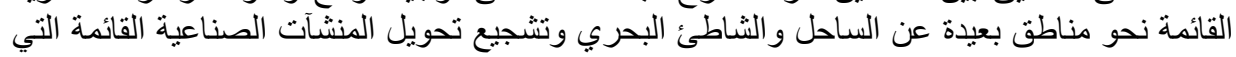

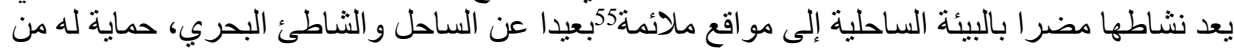

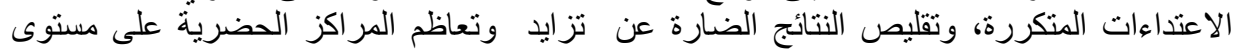

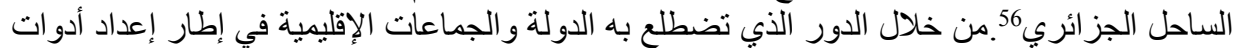

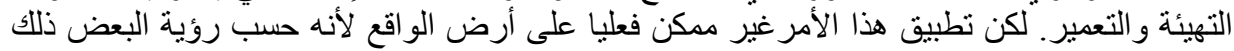
يرتبط بالقدرة الاقتصادية للبلد 57، وعليه نتطرق إلى كل من دور الدولة (1) ودور الجماعات الإلى الاقليمية

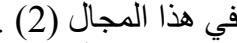

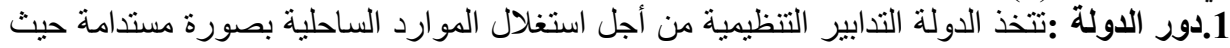

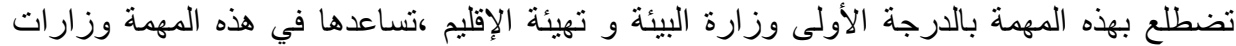

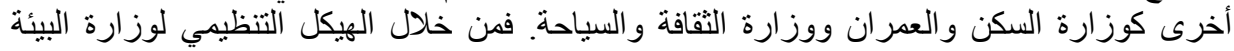

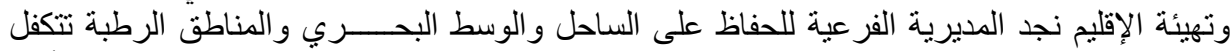

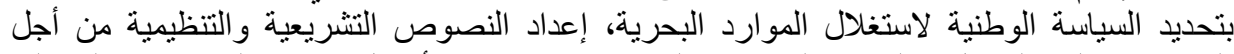

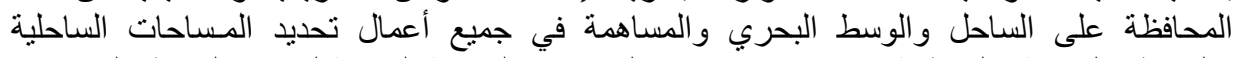

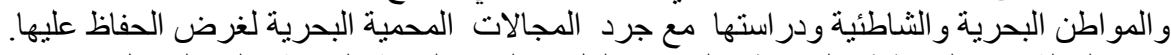

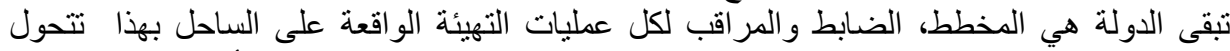

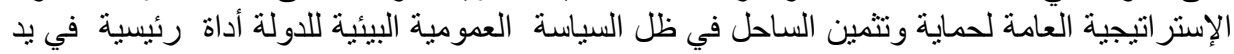

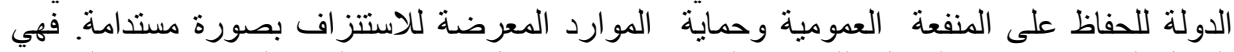

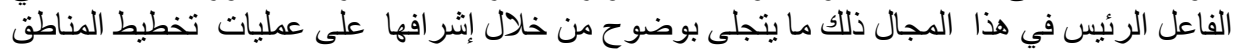

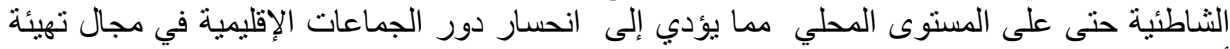
أوساطها الساحلية المحلية .مع خضوع الثناطية نشاطها لرقابة القاضي الإداري في حالة مخالفتهاً للقانون لكنه 
لا يسنطيع توجيه أو امر للإدارة و لا يمكنه التنخل دون رفع دعوى ، زيادة على خضوعها لرقابة

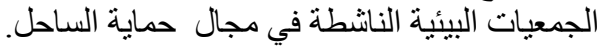

2.دور الجماعات الإقليمية:إن مسألة حماية البيئة الساحلية هي قضية محلية الكية أكثر منها قضية مركزية،

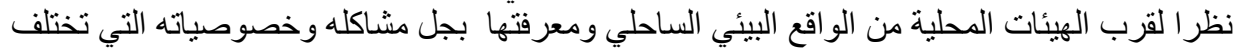

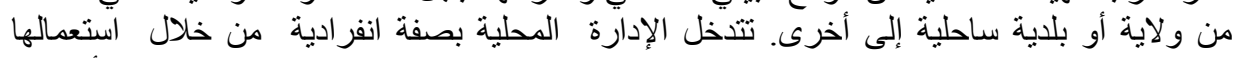

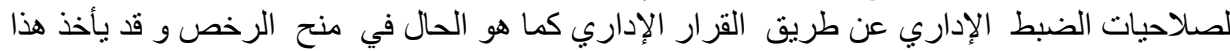

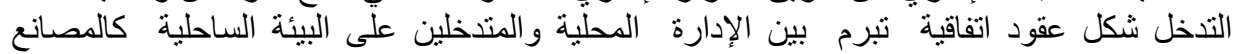

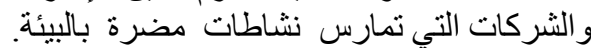

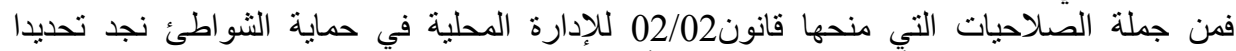

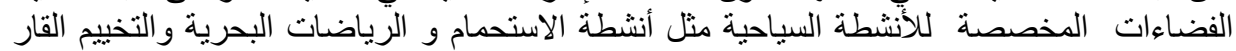

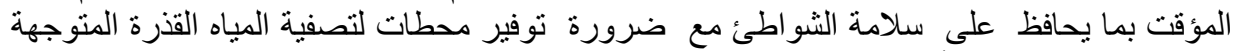

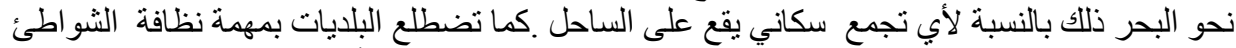

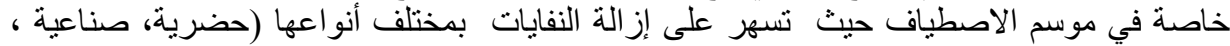

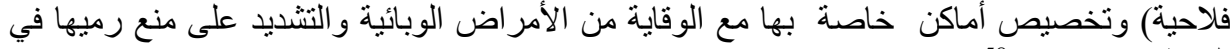

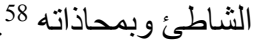

ثانيا : الهيئات العمومية ومهمة حماية العاحل.

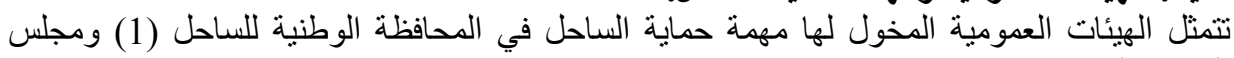
التنسيق الثناطئي(2). 1.المحافظة الوطنية للساحل:إن التلوث الذي تعرفه الثواطئ من خلال تصريف المياه القذرة

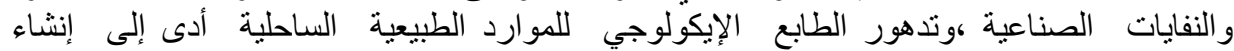

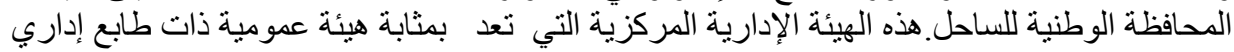

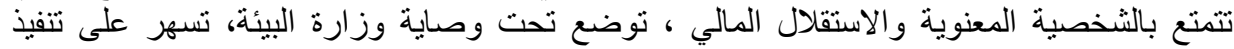

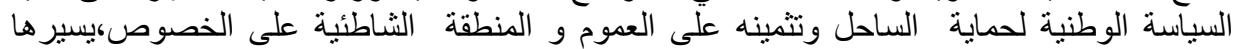

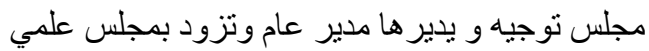

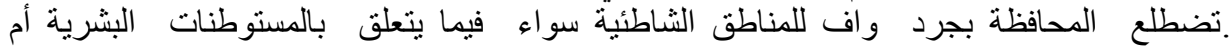

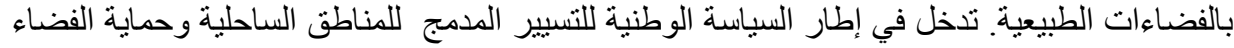

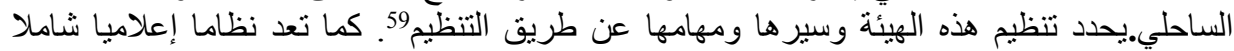

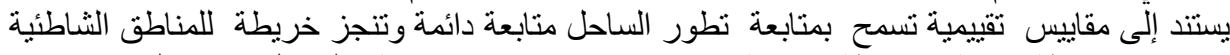

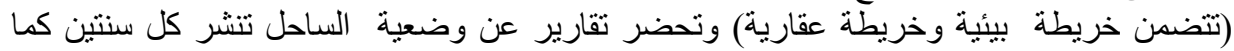
تجري تحاليل دورية لمياه الاستحمام وتعلم المستعملين لهارئية بنتائج التحاليل.

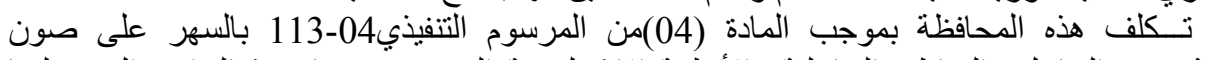

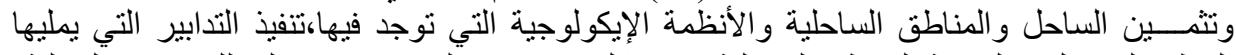

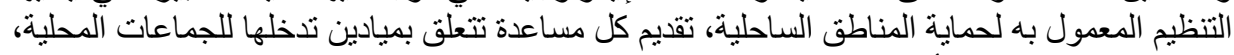

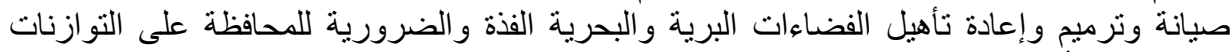

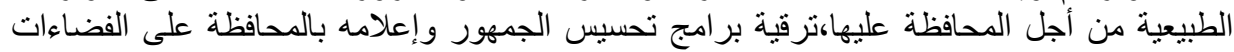

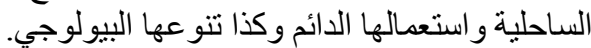

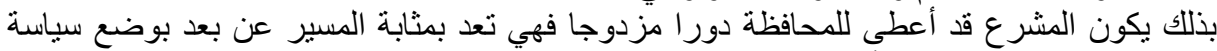

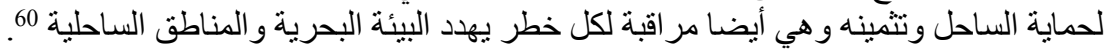

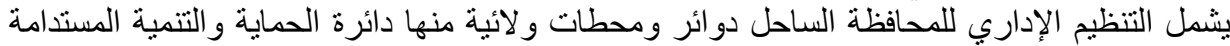

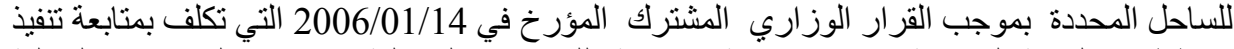
مخططات التهيئة السياحية، إنجاز ومتابعة نموذجية للمساحات الساحلية ، مساعدة الجماعات المحلية 


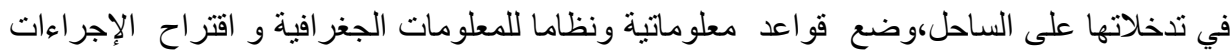

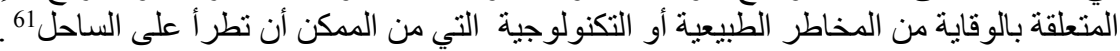

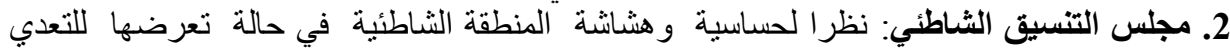

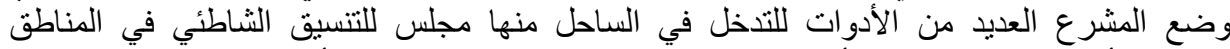

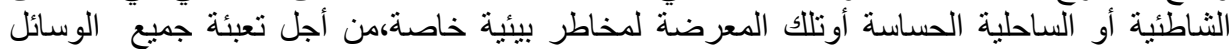

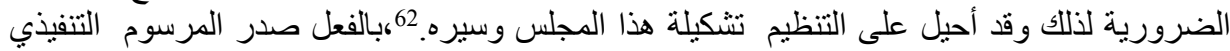

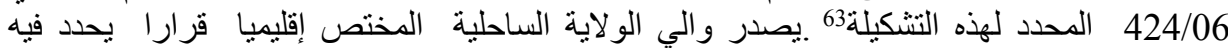

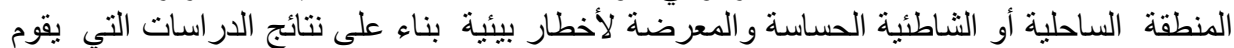

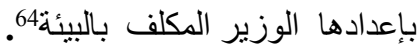

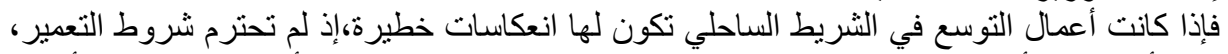

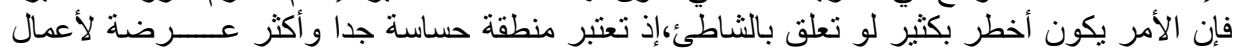

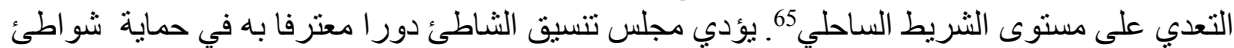

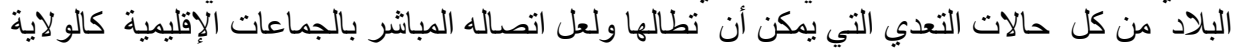

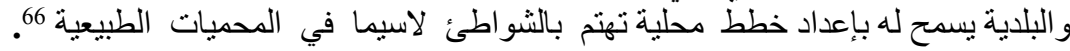

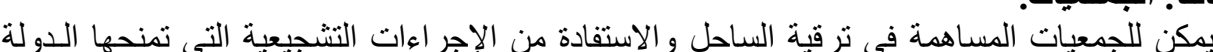

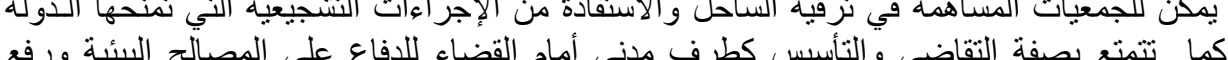

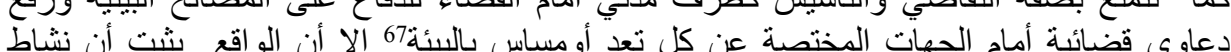

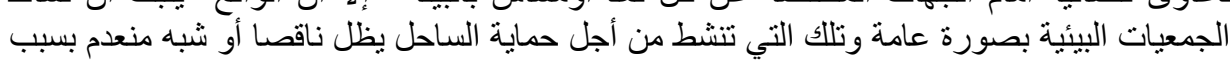

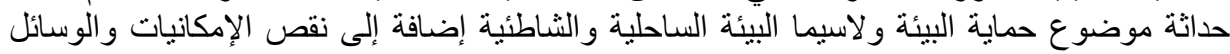

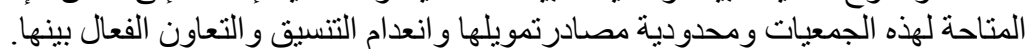
المطلب الثاني: الآليات القانونية العلاتية التاجية.

تتمثل الآليات القانونية العلاجية المجسدة للرقابة العابة البعدية في دور الموارد المانية المالية في تكريس هذه الحماية

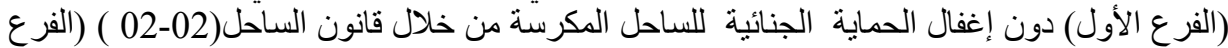

الفرع الأول:وسائل الحماية المالية.

إن الوسائل الضبطية التي توجد بيد الإدارة من أجل ضمانية الفئ حماية البيئة الساحلية هي الوسيلة المفضلة

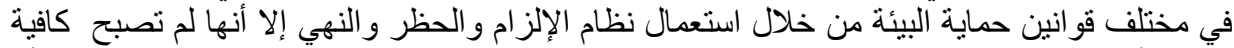

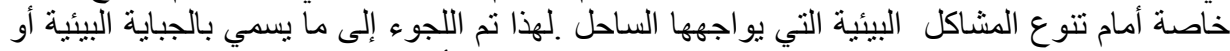

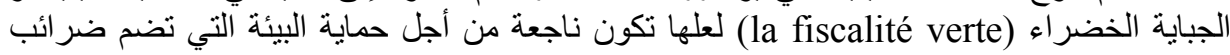
عديدة.

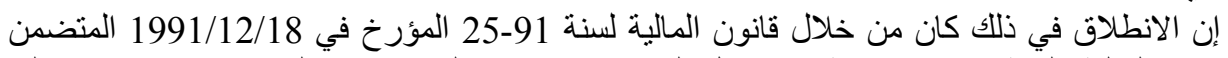

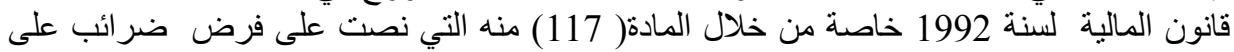

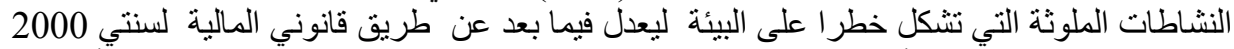

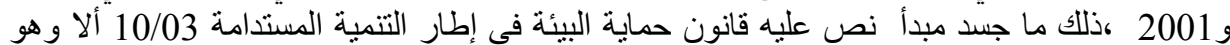

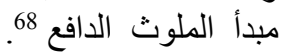
تجسد ذلك عمليا عن طريث تبني نظام الصناديق و الحسابات الخاصة وتأسيس صندوق وطني لحني لحماية

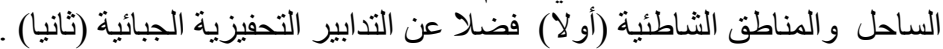
أولا: الصندوق الوطني لحماية الساحل و المناطق الثاطئية 69. 
ينشأ صندوق لتمويل تنفيذ التدابير المتخذة لحماية الساحل وفقا لقانون الساحل والمناطق الثاطئية

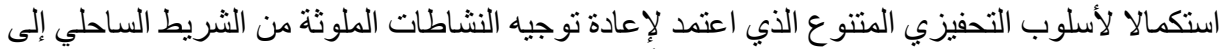

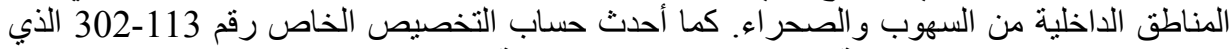

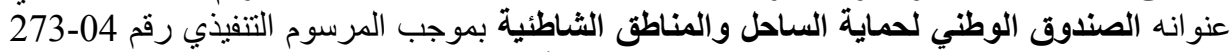

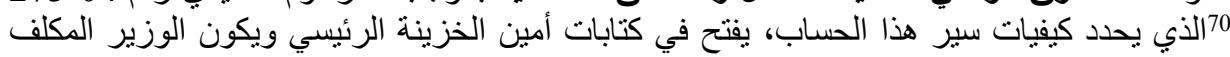

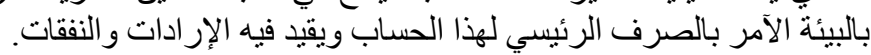

ثانيا: التدابير التحفيزية.

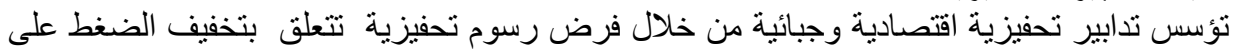

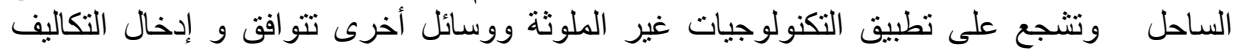

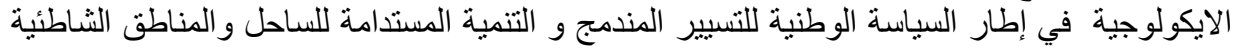

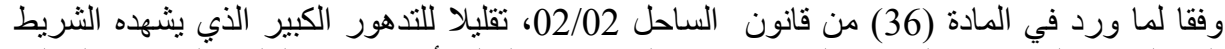

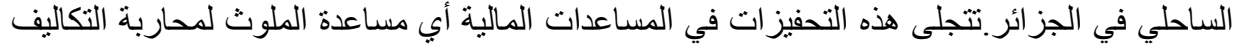

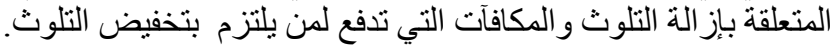

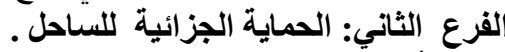

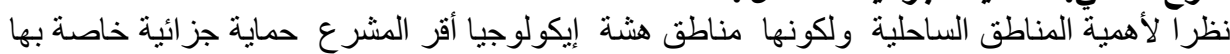

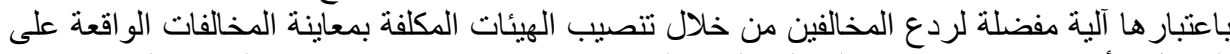

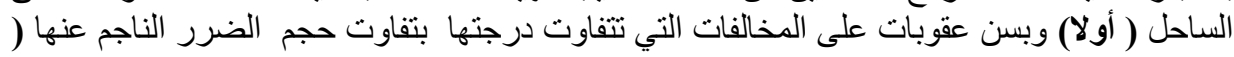

أولا: الهيئات المختصة بمعاينة المخالفات البيئية الواقعة على الساحل.

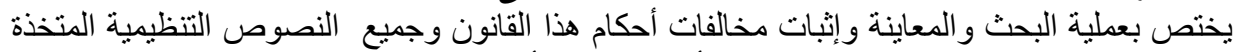

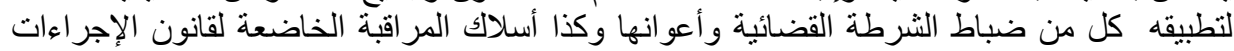

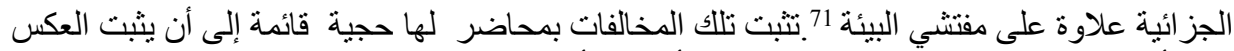

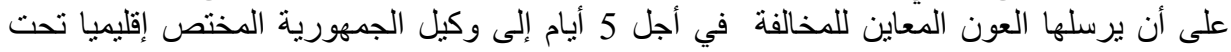

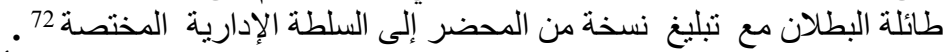

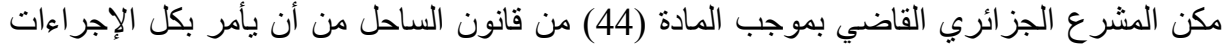

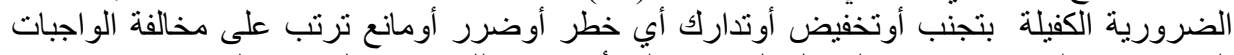

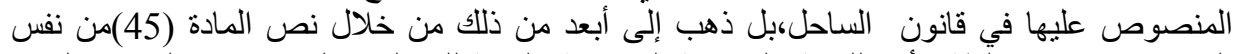

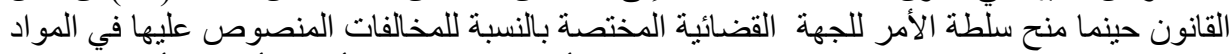

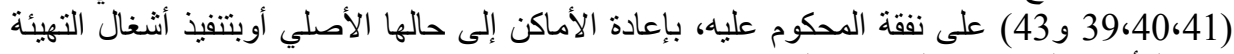
طبقا للأحكام التي نص عليها ذات القانون.

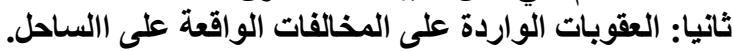

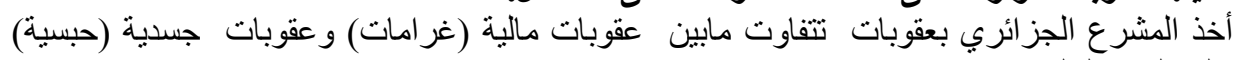

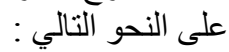

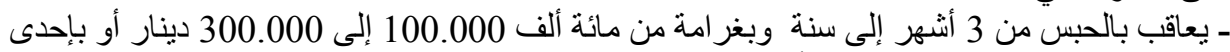

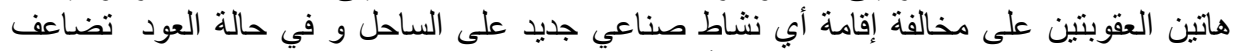

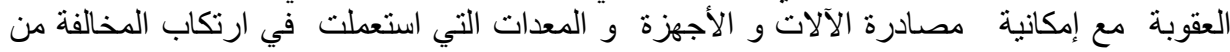

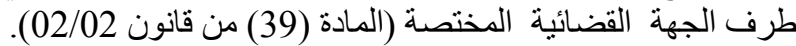

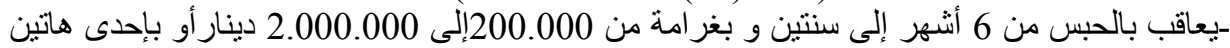
العقوبتين على كل عملية استخر اج لمو اد الملاط من الثناطئ وفي حالة العود تضاعف العقوبة (المادة 


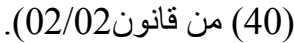

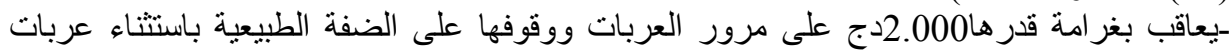

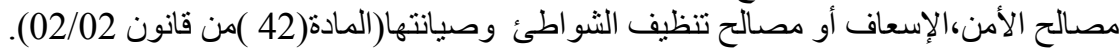

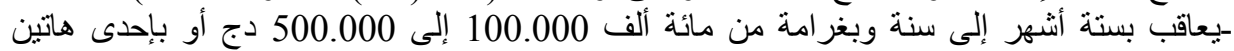

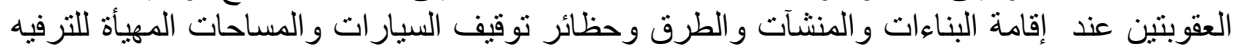

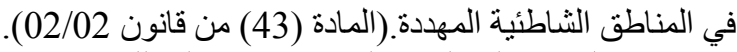

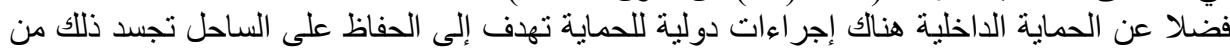

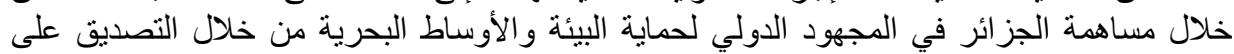

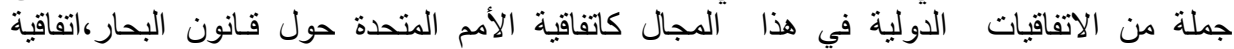
باريس،اتفاقية رامسارو اتفاقية برشلئونة

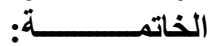

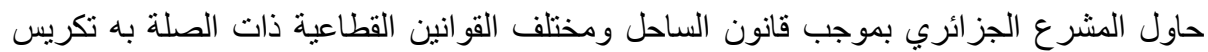

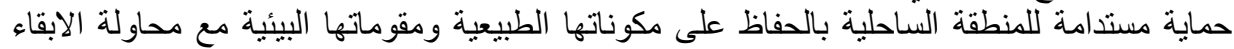

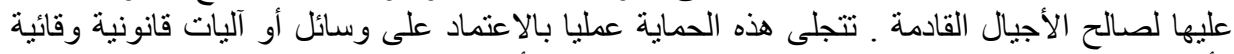

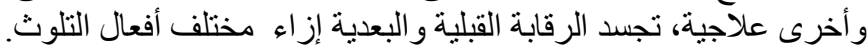

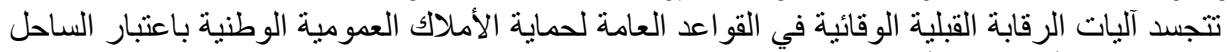

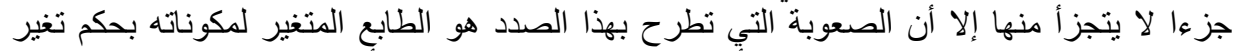

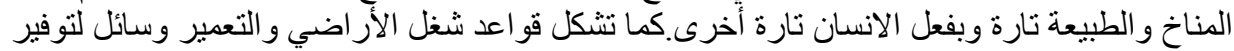

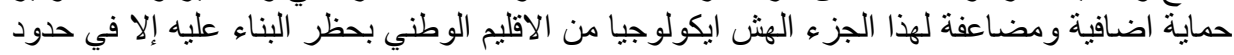

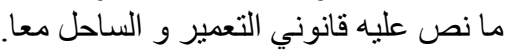

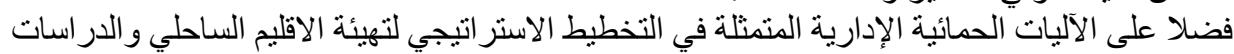

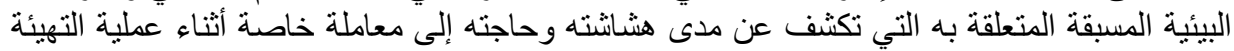

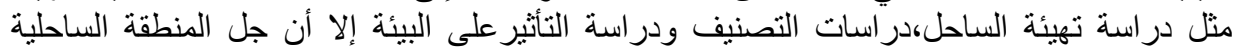

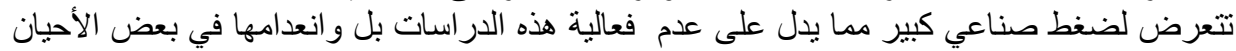
و إن وجدت فهي لا تؤخذ بعين الاعتبار من قبل السلطات المعنية لتفوق النظرة الاقتصادية التتموية على لئى حساب البيئة.

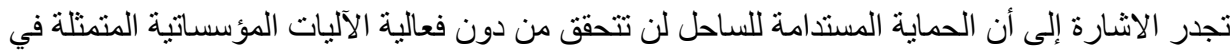

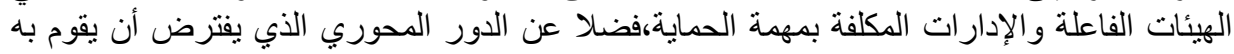

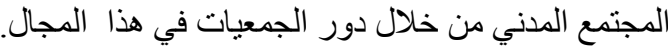

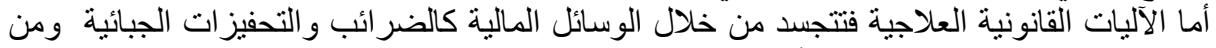

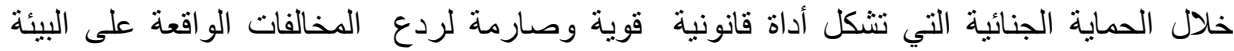
إلا أنه رغم الهجهودات المبذولة ييقى الساحل يعرف تدهور ا مستمرا و ومنظر ا باهتا بسبب الانتهاكات

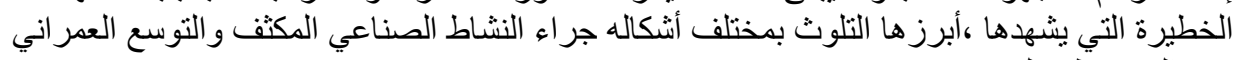

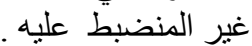

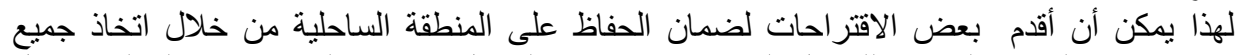

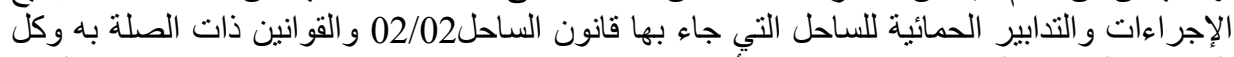

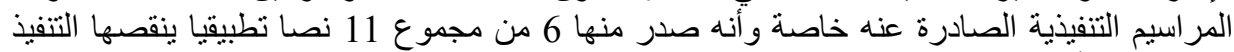

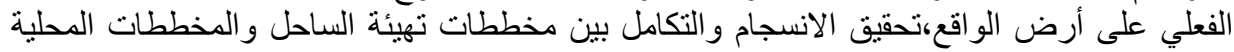

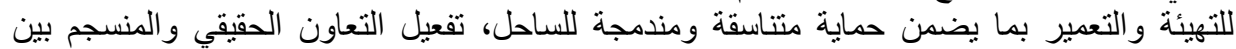
مختلف الأطر اف الفاعلة في مجال حماية الساحل وتثمينه و إعطاء صلاحيات أكبر للبلديات الساحلية في لئ 
تسيير شؤون سواحلها ،تعزيز الرقابة الصارمة على أنثغال التهيئة و التعمير من قبل الهيئات الإدارية

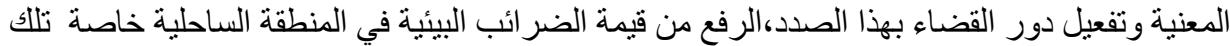

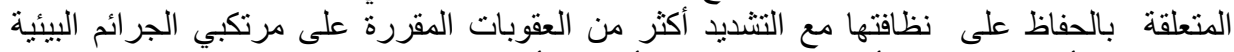

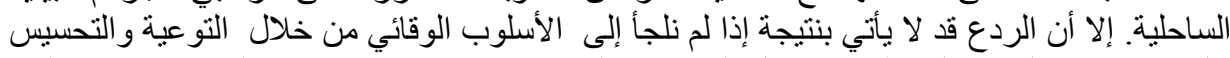

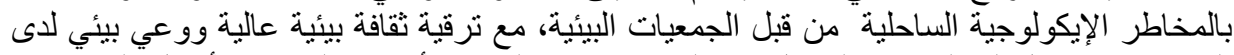

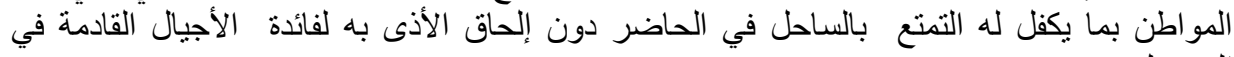

1. أشار القرآن الكريم قبل 14 قرنا إلى مصطلح الساحل وبوضوح في في الآية الكريمة39 من سورة

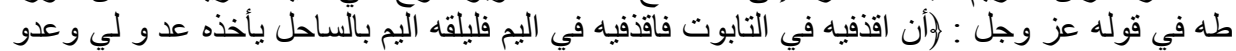

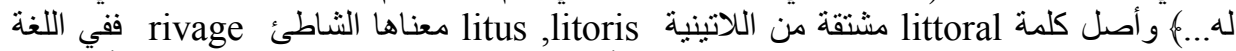

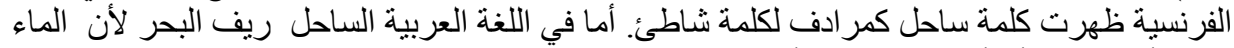

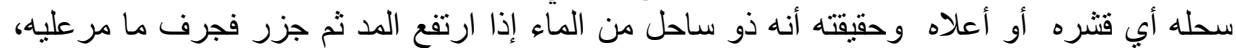

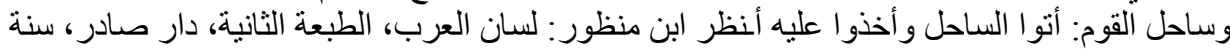

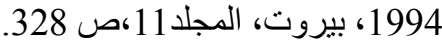

2. لقد نم إعادة قياس الساحل وتبين أن طوله يبلغ 1622 كلم بحساب المنعرجات هذا ما أكده قانون

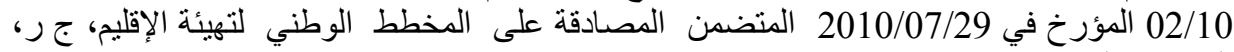

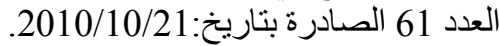

3.محضر المجلس الاقتصادي و الاجتماعي رأي حول ملف الجزائر غدا، أكتوبر سنة 1995، الجريدة

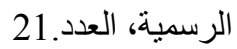

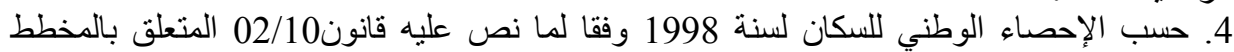

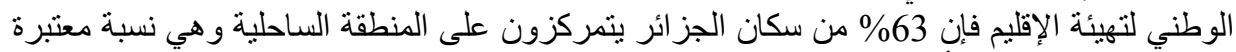

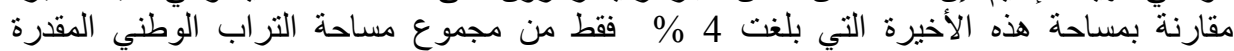
بـ

5. Cf. Rapport sur : "La ville Algérienne ou le devenir urbain du .CNES bulletin officiel no6,Octobre,1998,p153 pays »,12 ${ }^{\mathrm{èmè}}$ session du 6. قانون02/02المؤر خ في02 فبر اير 2002 المتعلق بحماية الساحل وتثمينه، الجريدة الرسمية ،العدد10

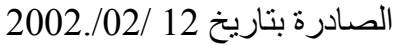

. Michel Hoddart : « entre terre et mer, les 250 ans du littoral », rapport 7 interne, France,Mai 2003,p08.

8.voir (Hamida) Merabet, dictionnaire de l'aménagement du territoire et de l'environnement, Berti éditions, Alger,sans date, p101. 9.Le littoral est une entité géographique qui appelle une politique spécifique d'aménagement de protection et de mise en valeur. Voir : Catherine Roche : l'essentiel du droit de l'environnement, $3^{\text {eme }}$ édition, Paris 2009,p48 et Agathe Van Lang: droit de l'environnement, presse universitaire de France , 1 ère édition, Paris, $2002, \mathrm{p} 343$.

10 .ر اجع المادة 44 من قانون 29/90 المعدل و المتمم التي نصت على الدفهوم القانوني للساحل قبل أن

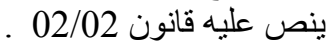

11.voir Boushaba (Abedlmadjid) :"l’Algérie et le droit des pêches maritimes", thèse pour le doctorat en droit international, Université Mentouri de 
Constantine,année 2008,p10.

12.القانون 175/62 المؤرخ في 1962/12/31 القاضي بسريان التشريع الفرنسي، ج ر ، عدد 11

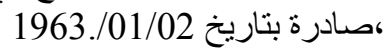

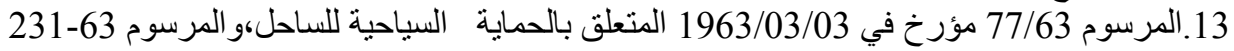

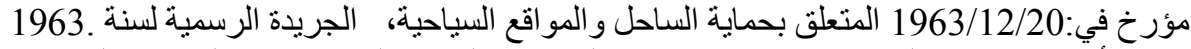

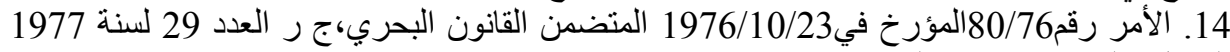

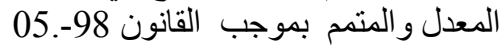
15.القانون 03/83 المؤرخ في 05فبر 98 اير 1983 المتعلق بحماية البيئة ؛ ج ر العدد 6 الملغى بموجب

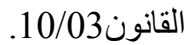

16.قانون29/90 المؤرخ في 1990/12/01 المنعلق بالتهيئة و التعمير المعدل والمتمم بموجب القانون

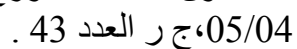
17.قانون 20/01 المؤرخ في 2001/12/12 المتعلق بتهيئة الاقليم وتتميته المستدامة ، جر العدد 77 2001. 18.قانون10/03المؤرخ في2003/07/19 المتعلق بحماية البيئة في إطار التتمية المستدامة،ج

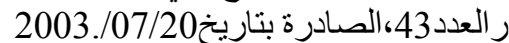
14.08 14/08 المؤرخ في 2008/07/20 المتعلق بالأملاك الوطنية ،جر، العدد44 الصادرة سنة 2008

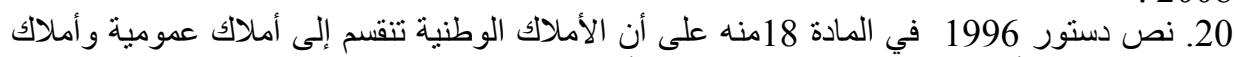

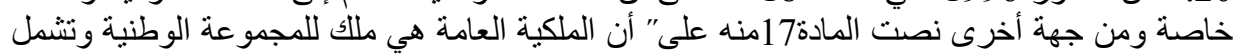

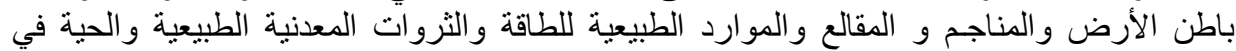

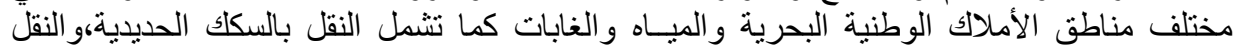

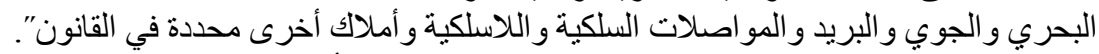

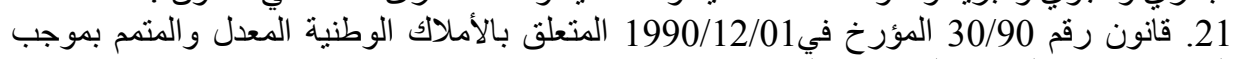

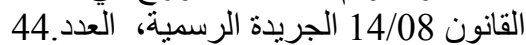

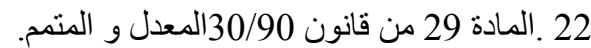

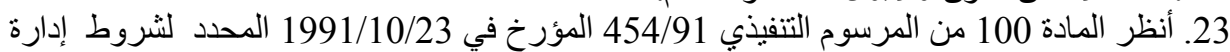

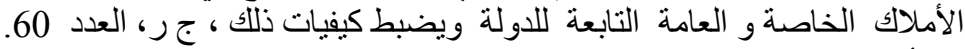

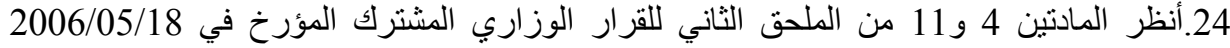

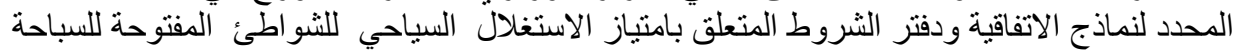

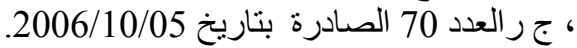

25.Cf.Rahmani (Ahmed) :"les biens publics en droit Algérien", les éditions internationales, Alger, 1996, p152. 26.voirBusson (B):"Loi littoral : les menaces

de féodalisation, la bétonisation", R.J.E,n ${ }^{\circ}$ spécial ,2004,p39. 27. هنوني (نصر الدين): " الحماية الراثدة للساحل في القانون الجزائري" ،دار هومه،الجزائر 782.

28.Cf.Kacemi (M):'La loi de protection et de valorisation du littoral en Algérie: cadre juridique ambitieux toujours en attente: le cas du pôle industriel d'Arzew(Oran-Algérie)",colloque international pluridisciplinaire, Le littoral: 04.«subir, dire, agir”,Lille, France,16-18janvier,2008,p 
29. Rahmani (Cherif): Le Plan National d'Action pour l'Environnement et le Développement Durable, (PNAE-DD), Ministère de l'aménagement du territoire et de l'environnement, janvier ,2002,p 43.

30. القانون 02/10 المؤرخ في 2010/06/2010 يتضمن المصادقة على الهخط الوطني لتهيئة الإقليم،ج 2010. رالعدد 61 المؤرخة في 21 أكتوبر في المير

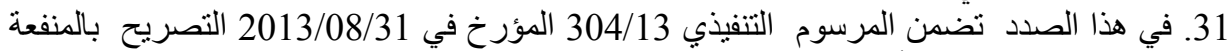

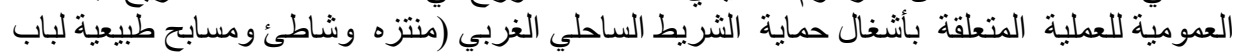

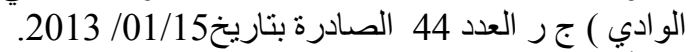

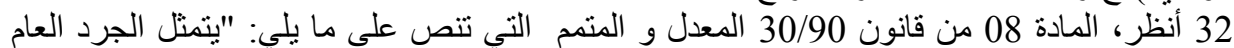

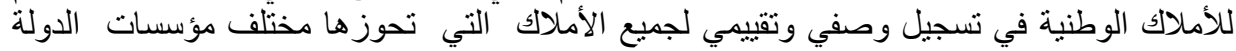

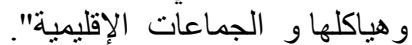

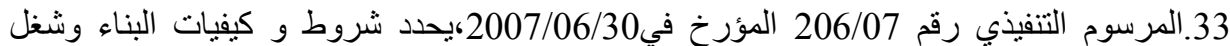

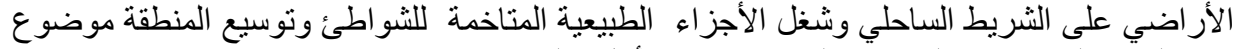

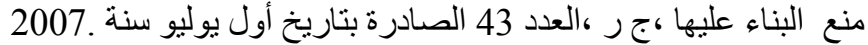

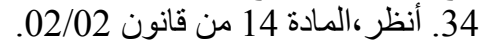
35. أنظر/،المادة 12 و المادة 13 من قانون 30 من المانون 02/02/02 36. 35. أنظر، المادة 30 من قانون 18 من المادة

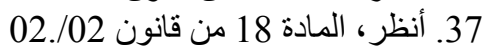

Les conditions .. Cf.Adja(Djilali),Drobenko(Bernard) : "Droit de l'urbanisme38 de l'occupation du sol et de l'espace, L'aménagement-le contrôle-le financement-le contentieux ",Berti éditions, Alger, 2007, p126 39.أنظر، القانون رقم 01/03 المؤرخ في 2003/02/17 يتعلق بالتنمية المستدامة للسباحة ،الجريدة

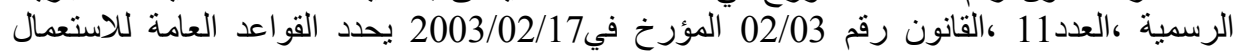

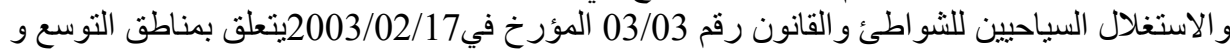
المو اقع السياحية ، الجريدة الرسمية ،نفس العدد.

: "Les relations entre le droit de l'urbanisme et le droit)Hélène(.BRANCO40 de l'environnement sur le littoral", Thèse pour le doctorat en droit public , UNIVERSITE DU SUD TOULON-VAR U.F.R. DROIT, Centre de Droit et de Politique Comparés Jean-Claude Escarras, (C.N.R.S.- U.M.R. 6201) Présentée 45et soutenue publiquement le 14 juin 2013 ,p 41.أنظر تعريف الثناطئ في نص المادة 3 من القانون 02/03 .

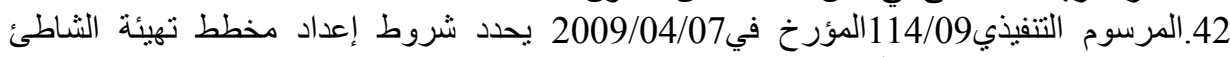

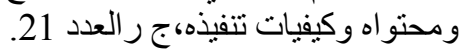

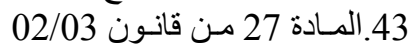

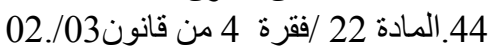
45. 45 المادة 52 من قانون 42.03

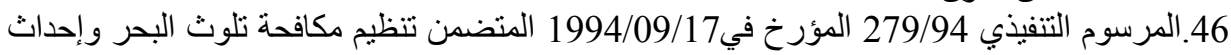

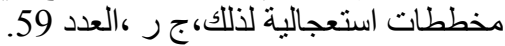

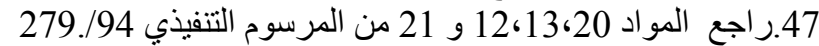

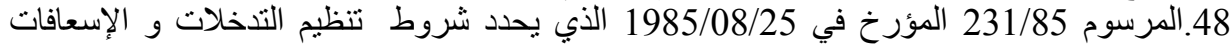

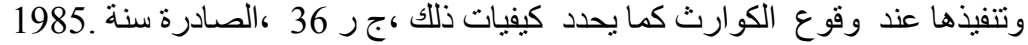




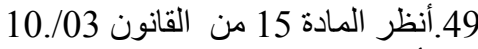

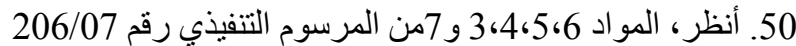

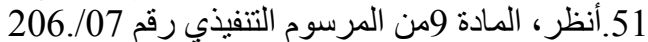

$$
\begin{aligned}
& \text { 52.أنظر المادة } 4 \text { من المرسوم المن المرسوم التفيذي 206/07. }
\end{aligned}
$$

53.أنظر،المادة 3 من المرسوم التنفيذي 88/09 المؤرخ في 2009/02/17 المتعلق بتصنيف المناطق

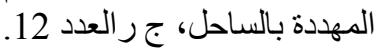

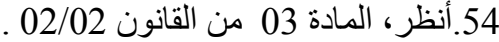

55.أنظر، المادة 4 من قانون 02.02

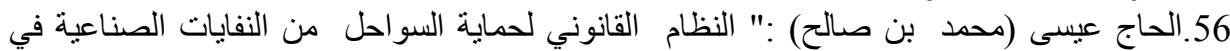
التثريع الجزائري" ، مذكرة ماجستير ، كلية الحقوق و العلوم السياسية ، جامعة الجز ائر ،2009/2008 النيات

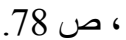
57.شكيوة (عثمان):"الحماية القانونية للساحل"،الملتقى الوطني الأول حول التهيئة العمرانية في

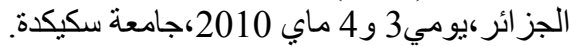
58.أنظر ، المادة 12 من قانئون

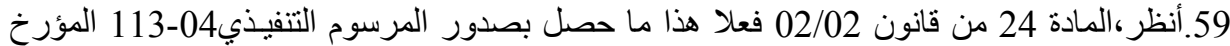
في2003/04/13 المتضمن تنظيم المحافظة الوطنية للساحل وسير ها ومهامها الجريدة الرسمية العدد العدان

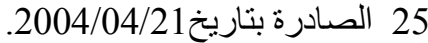

60. أنظر، سعيدان (علي): "حماية البيئة من التلوث بارث بالمواد الإشعاعية والكيماوية في القانون

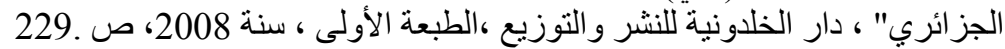
61. أنظر، المادة 04 من القرار الوزارئ الترزيع المؤرخ في 2006/01/14 المنضمن التنظيم الإداري

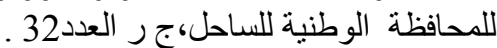

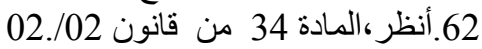
63. يضيف التعديل الو ارد بموجب المرسوم التنفيذي رقم 122/08 المؤرخ في :2008/04/15ممثلا

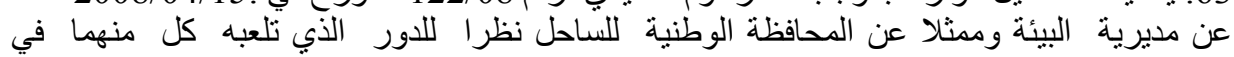
تكريس الحماية الإدارية للساحل.

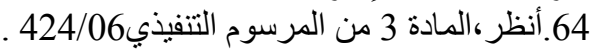
65.حمزة أحمد (هيثم): المناطق الحساستة السيطرة العقارية في الثريط الساحلي،مذكرة ماجستير،كلية

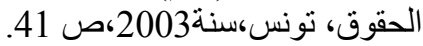
66 .دوار (جميلة) :"النظام القانوني للمدينة في التشريع الجزائري"، رسالة دكتوراه كلية الحقوق،

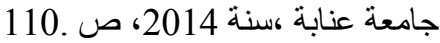
67. أنظر ، المادتين 36 و 37 من من قانون 10/03، 10/10 .

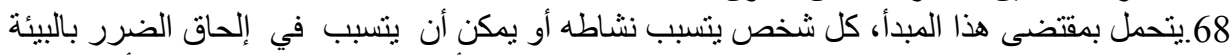

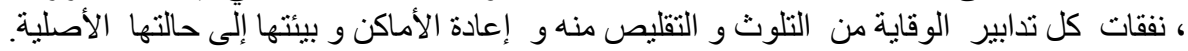

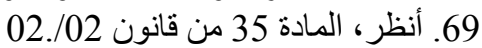

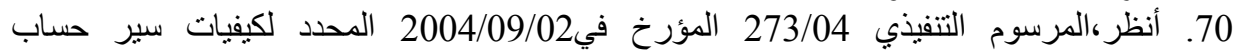

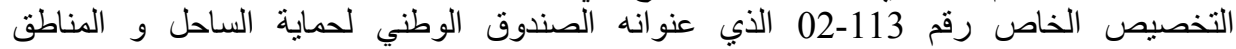

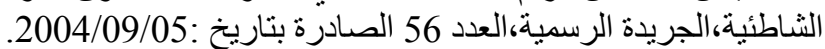

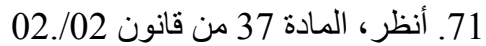

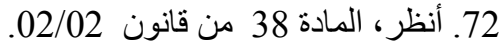

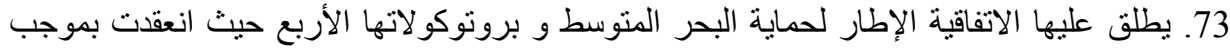

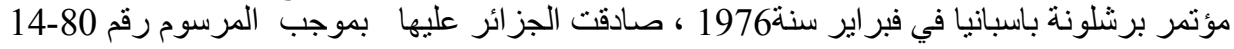




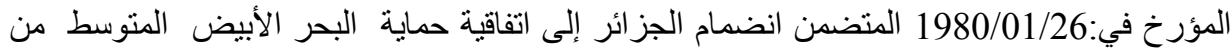

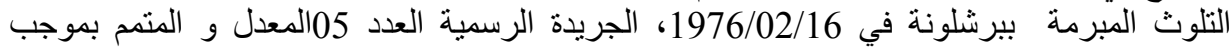
المرسوم الرئاسي 141/04 ،جرة في عدد في 